\title{
Analysis on Forced Vibration of Thin-Wall Cylindrical Shell with Nonlinear Boundary Condition
}

\author{
Qiansheng Tang, Chaofeng Li, and Bangchun Wen \\ School of Mechanical Engineering \& Automation, Northeastern University, Shenyang 110819, China \\ Correspondence should be addressed to Chaofeng Li; chaof.li@gmail.com
}

Received 24 March 2016; Revised 6 June 2016; Accepted 15 June 2016

Academic Editor: Marcello Vanali

Copyright (C) 2016 Qiansheng Tang et al. This is an open access article distributed under the Creative Commons Attribution License, which permits unrestricted use, distribution, and reproduction in any medium, provided the original work is properly cited.

\begin{abstract}
Forced vibration of thin-wall cylindrical shell under nonlinear boundary condition was discussed in this paper. The nonlinear boundary was modeled as supported clearance in one end of shell and the restraint was assumed as linearly elastic in the radial direction. Based on Sanders' shell theory, Lagrange equation was utilized to derive the nonlinear governing equations of cylindrical shell. The displacements in three directions were represented by beam functions and trigonometric functions. In the study of nonlinear dynamic responses of thin-wall cylindrical shell with supported clearance under external loads, the Newmark method is used to obtain time history, frequency spectrum plot, phase portraits, Poincare section, bifurcation diagrams, and threedimensional spectrum plot with different parameters. The effects of external loads, supported clearance, and support stiffness on nonlinear dynamics behaviors of cylindrical shell with nonlinear boundary condition were discussed.
\end{abstract}

\section{Introduction}

Circular cylindrical shell structures are commonly used in various engineering applications in the aerospace, petrochemical engineering, marine, and so on. Their axisymmetric bodies are easy to manufacture and they have advantages to improve the structure's ability. In these applications, shell structures are commonly subjected to various dynamic loads. Therefore, a great deal of interest for linear and nonlinear vibration analysis of cylindrical shell is being manifested in the specialized literature.

Some studies early reported in the literature were about free vibration of cylindrical shell with classical boundary condition, such as simply supported-simply supported, freefree boundary, clamped-clamped, clamped-free, and clampsimply supported. In the monograph by Leissa [1], a thorough review of a series of solution techniques provided for shell structure based on various shell theories, including Donnell's theory, Flügge's theory, Love's theory, and Sanders' theory. Qatu $[2,3]$ made a conclusion of research advance in dynamic behavior of shells from 1989 to 2000 . He pointed out many methods for studying cylindrical shell dynamics, obtaining natural frequencies and mode shapes. Others as Loy et al. [4-6] studied the free vibration of cylindrical shell using differential quadrature method, analyzed the effects of boundary condition on frequencies of a multilayered cylindrical shell, and compared the vibration characteristics of rotating laminated cylindrical shells based on different thin shell theories. Pradhan et al. [7] studied free vibration of functionally graded cylindrical shell using energy method and Ritz method based on Love's shell theory. The beam function and trigonometric function were utilized to express the displacements of shell. Zhang et al. [8] presented the analysis of vibration of cylindrical shell using wave propagation method. Many other methods were used for the vibration analysis of cylindrical shell.

Forced vibration of cylindrical shell with classical boundary condition is also of concern for a long time. Based on firstorder shear deformation theory, Khan et al. [9] performed the vibration analysis of clamped-clamped cylindrical shells using finite element method. New and Bert's constitutive models were used to study the influence of radius to thickness ratio and the number of layers on the vibration characteristics. Du et al. [10] used the Lagrangian theory and multiple scale method to investigate the nonlinear dynamic behaviors of infinitely long functionally graded cylindrical shells based on Donnell's nonlinear shell theory. The amplitude-frequency curves and the bifurcation behaviors of the system were 


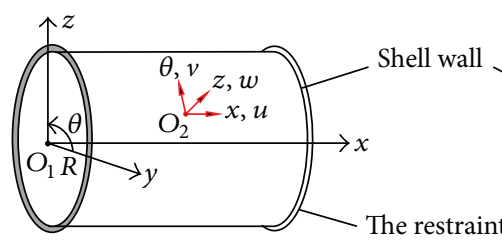

(a)

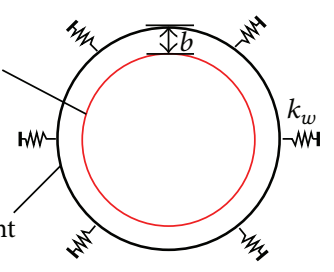

(b)

FIgURE 1: Coordinate system of a cylindrical shell with a supported clearance at one end.

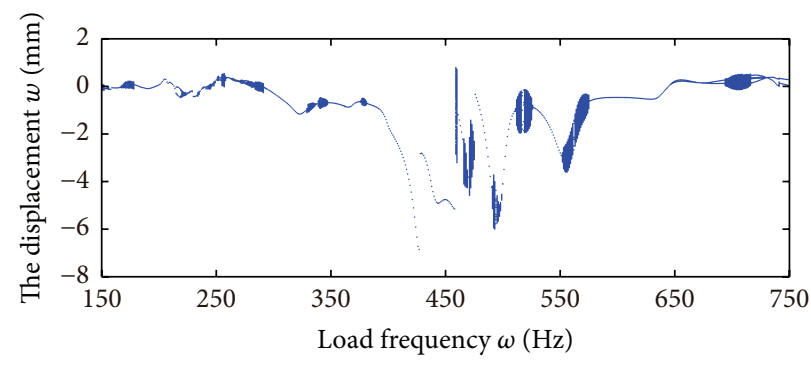

Figure 2: The bifurcation diagram of $\omega$ versus $w b=0.1 \mathrm{~mm}$.

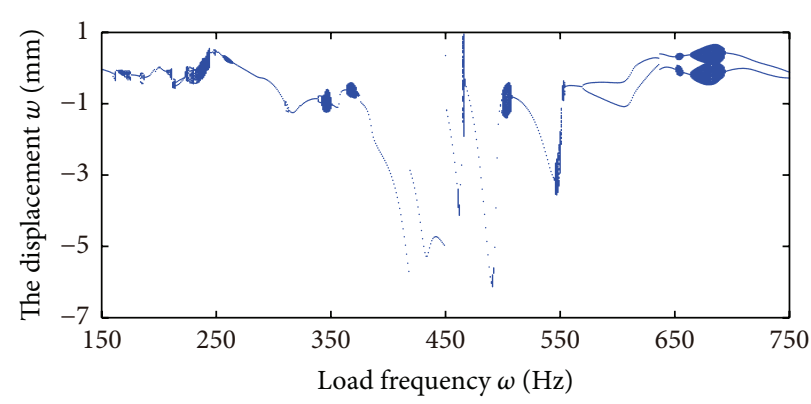

FIGURE 3: The bifurcation diagram of $\omega$ versus $w$ under $b=0.2 \mathrm{~mm}$.

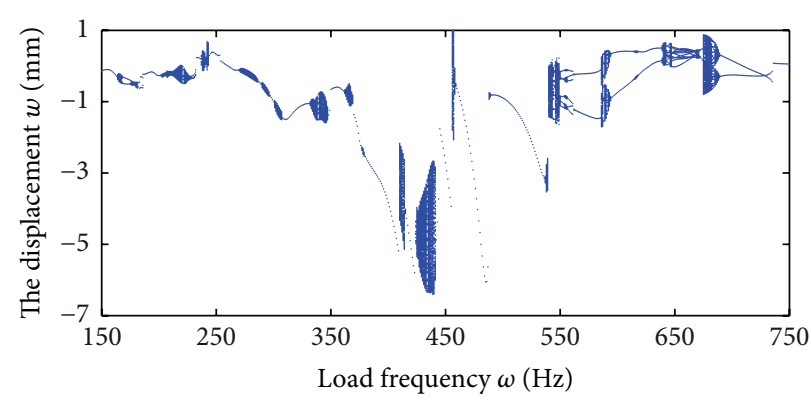

FIGURE 4: The bifurcation diagram of $\omega$ versus $w$ under $b=0.3 \mathrm{~mm}$.

discussed under different parameters. Qu et al. [11] applied a domain decomposition technique to vibration problem of uniform and stepped cylindrical shells. Free and forced vibration of shell were examined under different boundary conditions and the forced response of shell was presented with different influence factors. Dai and Jiang [12] presented an analytical solution for forced vibration of a FGPM cylindrical shell and the effects of electric excitation, thermal load, mechanical load, and volume exponent on the static and dynamic behaviors were discussed. Sofiyev [13] studied the dynamic characteristics of FGM cylindrical shell subjected to moving loads with different material property gradient, radius to thickness ratio, and velocity of the moving load. Salahifar and Mohareb [14] analyzed the vibration of circular cylindrical shell under harmonic force and several examples were presented. Liu et al. [15] studied the nonlinear dynamic behaviors of a simply supported FGM cylindrical shell under complex loads and bifurcation behaviors were discussed in detail. Ibrahim et al. [16] carried out the periodic response of cross-ply composite curved beams using finite element 


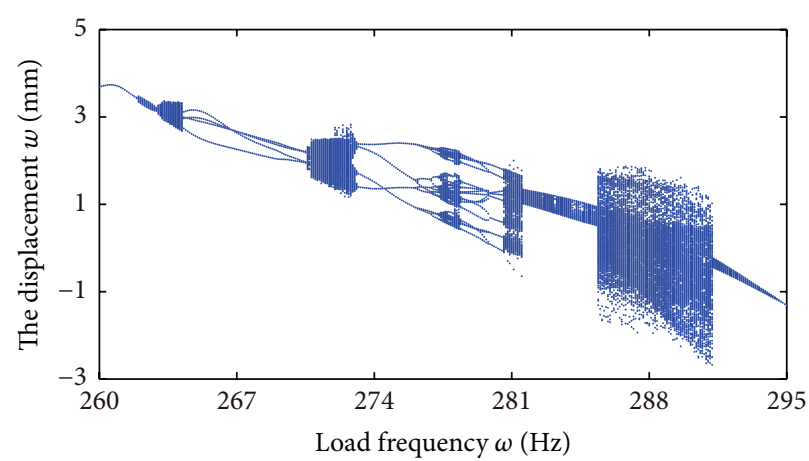

(a)

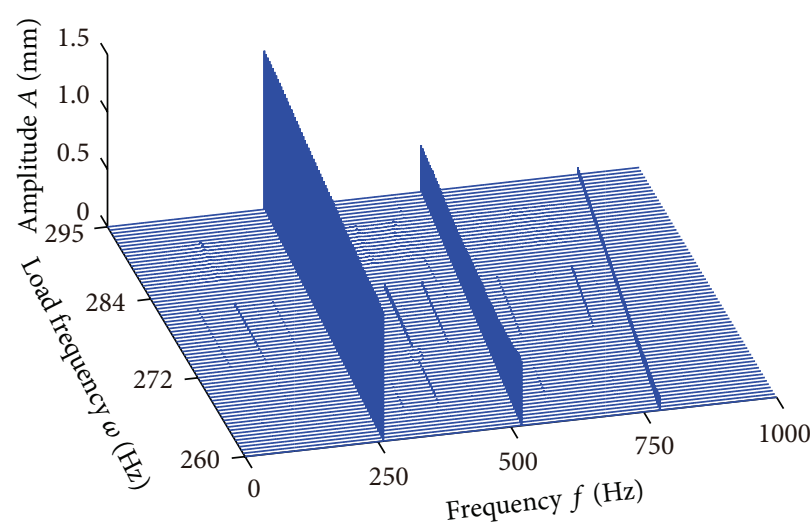

(b)

FIGURE 5: The bifurcation diagram and the three-dimensional spectrum plot when $260 \mathrm{~Hz} \leqslant \omega \leqslant 295 \mathrm{~Hz}$.

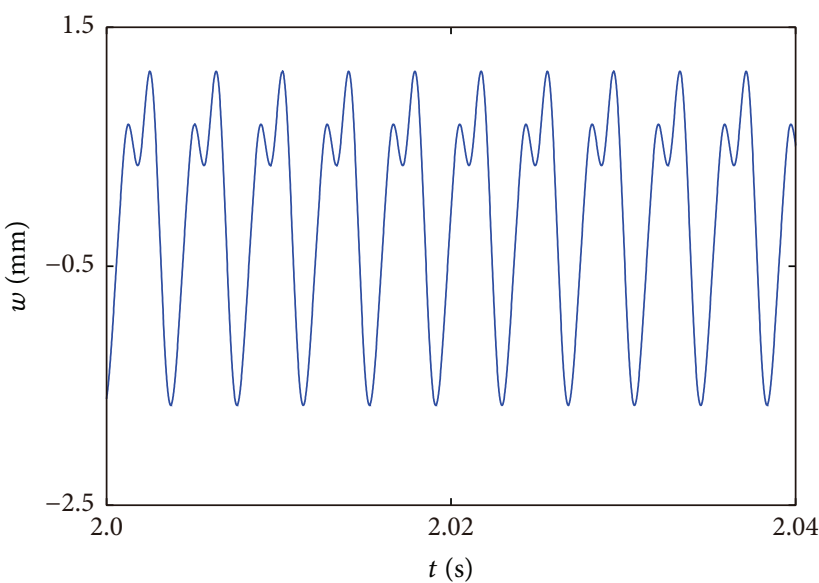

(a) Time history

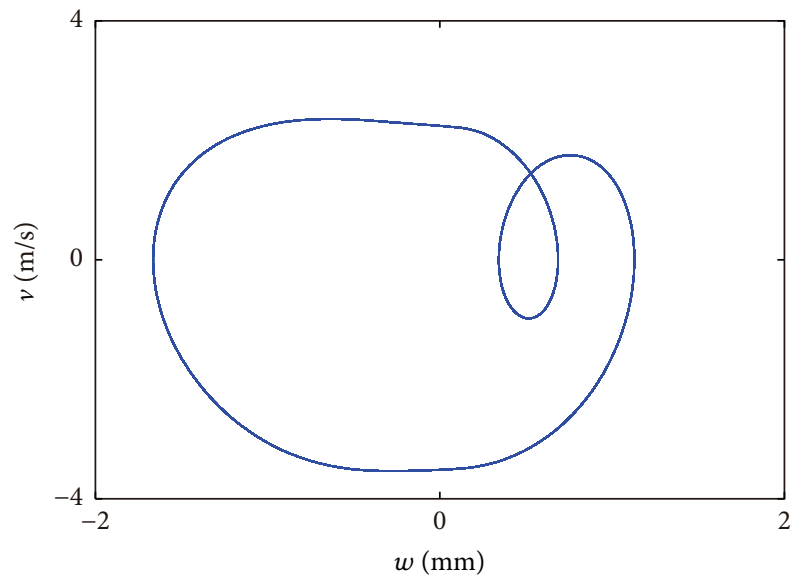

(c) Phase portraits

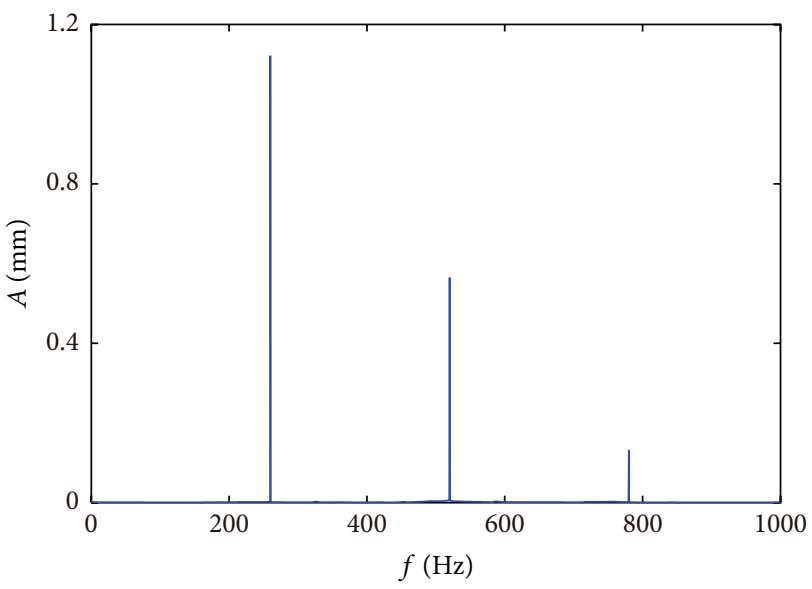

(b) Frequency spectrum plot

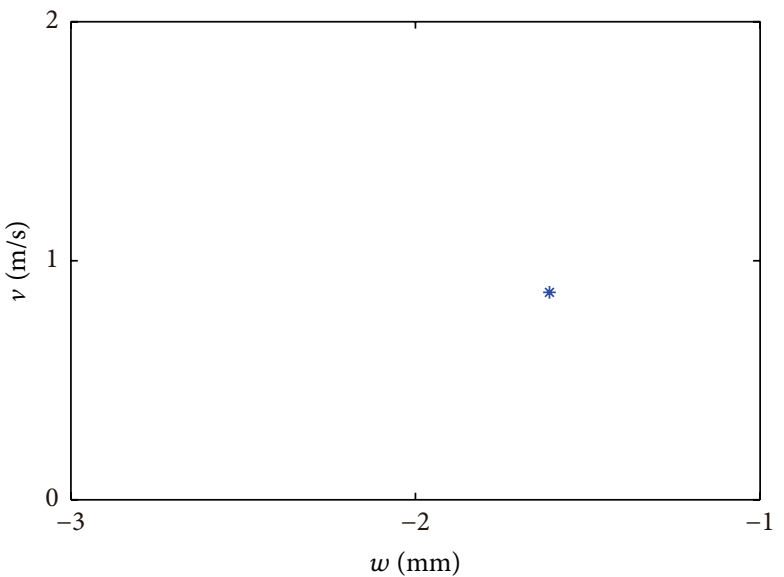

(d) Poincare section

FIgURE 6: The periodic motion of cylindrical shell at $\omega=260 \mathrm{~Hz}$.

method based on higher-order shear deformation theory and the frequency of harmonic excitation is in the neighborhood of symmetric and antisymmetric linear free vibration modes. The shooting technique coupled with Newmark time marching and the arc length continuation algorithm were used to integrate the governing equations. And then they [17] applied those methods into the analysis of nonlinear response of symmetrically and nonsymmetrically excited oval cylindrical shells and integrated the effect of loading locations and ovality parameter on the steady state frequency response 


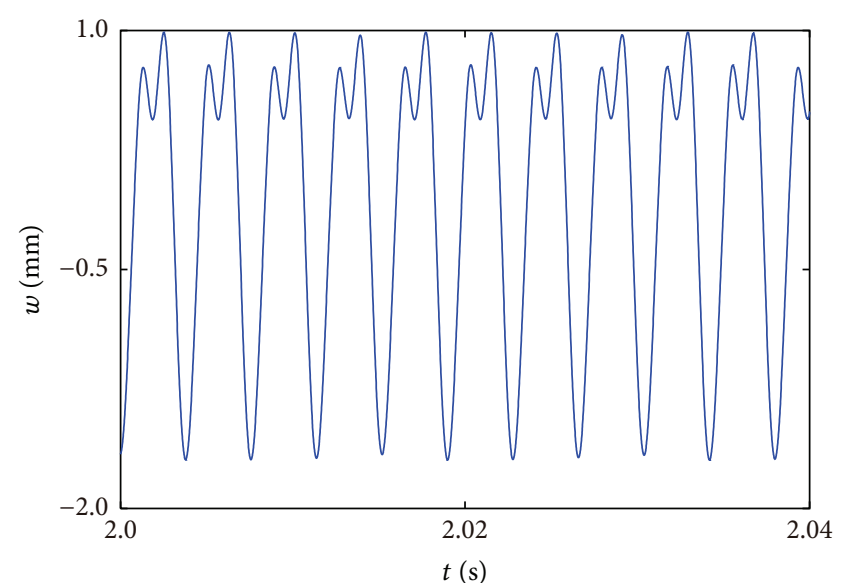

(a) Time history

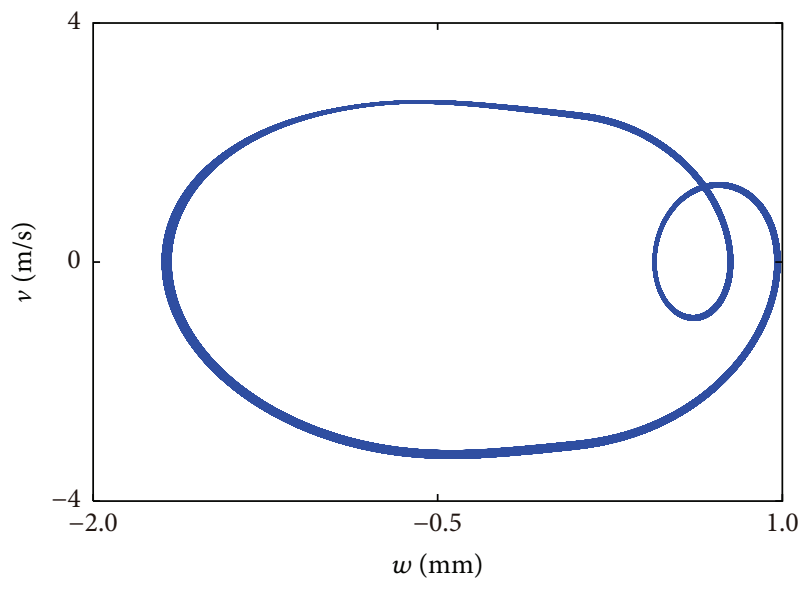

(c) Phase portrait

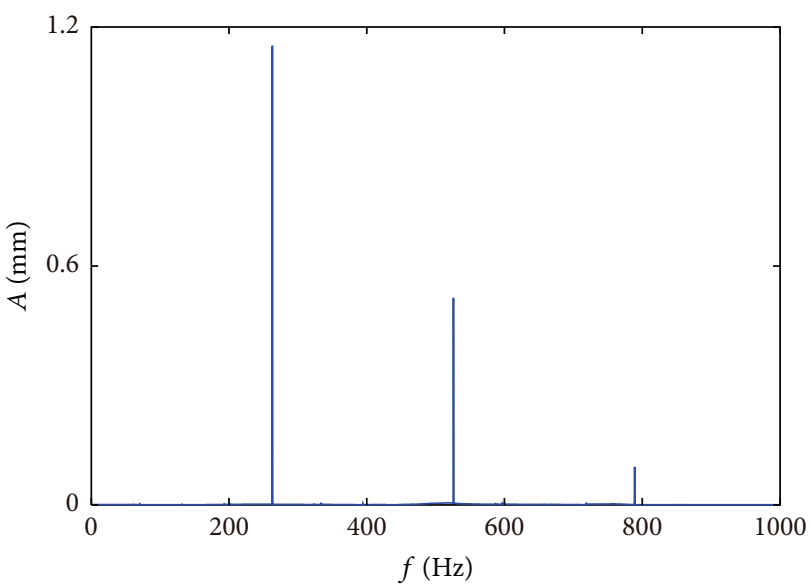

(b) Frequency spectrum plot

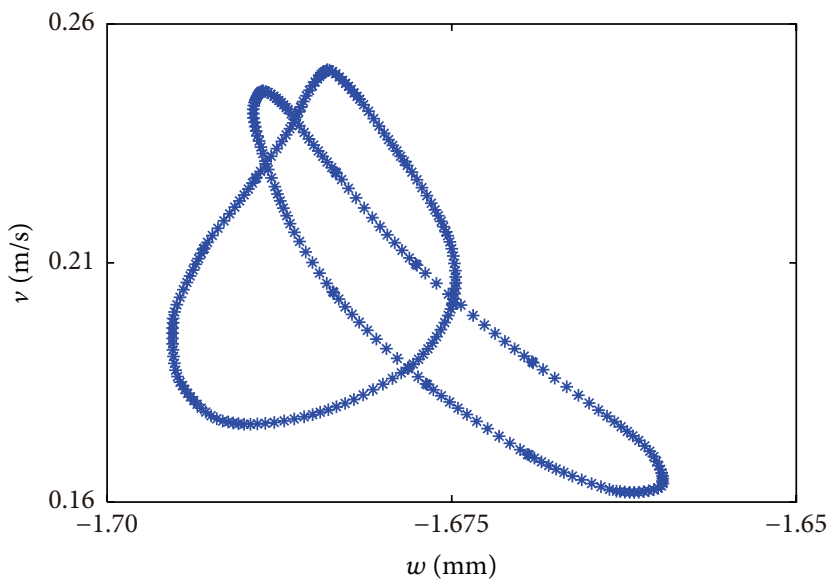

(d) Poincare section

FIgURE 7: The chaotic motion of cylindrical shell at $\omega=263 \mathrm{~Hz}$.

and modal participation factors. Singh et al. [18] applied the semianalytical finite element method into the rotating crossply laminated shells. They studied the influence of meridional curvature on its buckling and postbuckling behaviors under thermal and mechanical loads and found softening or hardening nonlinearity under different conditions.

As studying deeply on the vibration of circular cylindrical shell, complicated boundary conditions, such as elastic boundary conditions, are attracting attention of researchers. To analyze the dynamic characteristics of cylindrical shell with elastic constraints, artificial springs are usually utilized by many researchers. The boundary condition for each point at the edges is represented as four sets of independent springs, including three sets linear springs and one set of rotational springs, and through setting different spring stiffness, different boundary conditions can be simulated.

Recently, an energy oriented modified Fourier method was used to solve the elastic boundary problem. The key point in this method was that, regardless of boundary conditions, each of the displacements and rotation components of the shell can be expanded as the linear combination of a standard Fourier series and several supplementary terms, which were introduced to ensure and accelerate the convergence of the series expansions. Dai et al. [19] developed the modified Fourier series for the free vibration of a clamped elastically supported shell based on Flügge's shell theory and the modal properties of shell were shown with different radial spring stiffness at the elastic end. Zhou et al. [20] applied the method of wave propagations to investigate the effects of elastic restraints on the frequency parameters for cylindrical shells of different geometrical characteristics. Jin and his coauthors [21-25] used this energy oriented modified Fourier method to carry out the vibration problem of isotropic and composite structures with general boundary conditions. The effects of restraining stiffness, shear parameter, lamination schemes, and other related factors on the vibration characteristics of different structures were shown. For example, they had analyzed the vibration of a three-layered passive constrained layer damping cylindrical shell Based on Donnell's shell assumptions and linear viscoelastic theory [21], the vibration of composite laminated cylindrical shells with arbitrary lamination schemes [22], the vibration of moderately thick composite laminated cylindrical shells with arbitrary intermediate ring supports under elastic boundary conditions 


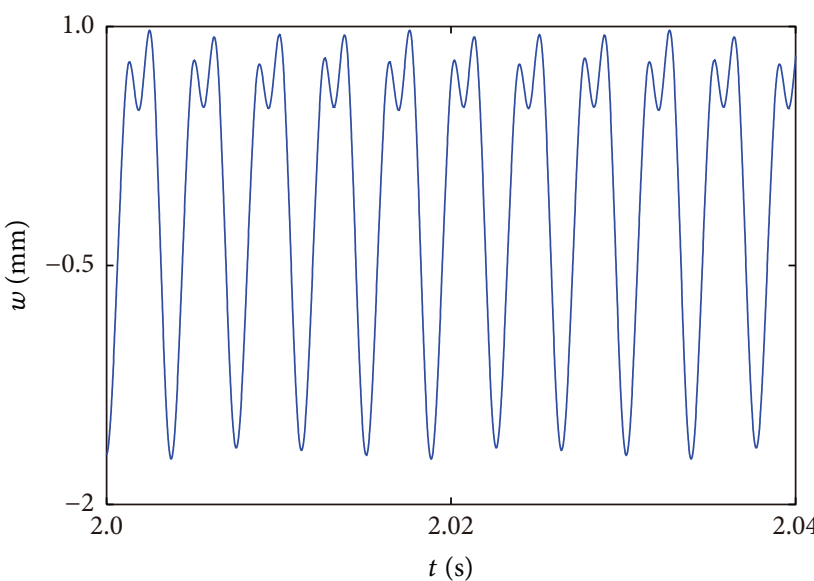

(a) Time history

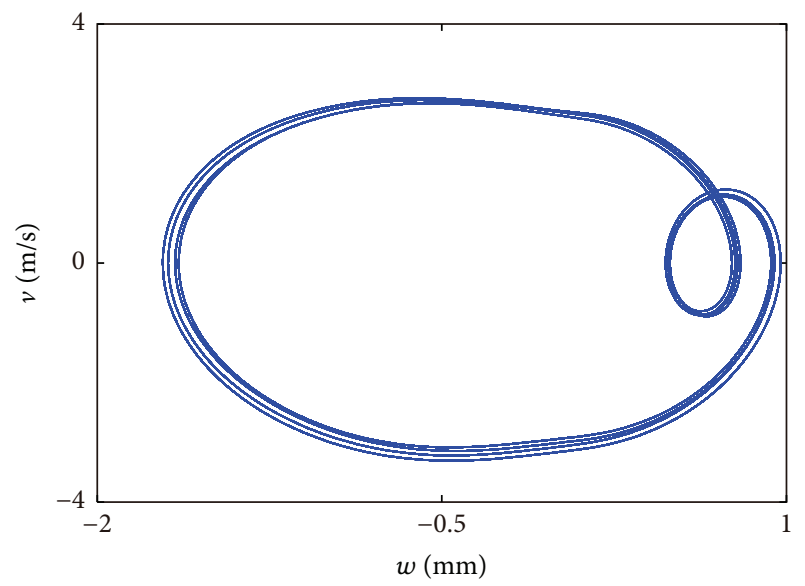

(c) Phase portrait

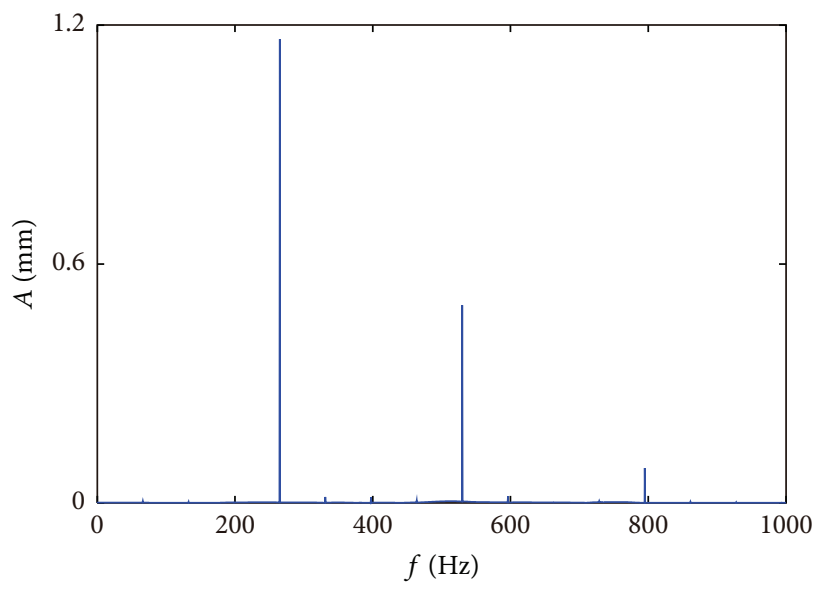

(b) Frequency spectrum plot

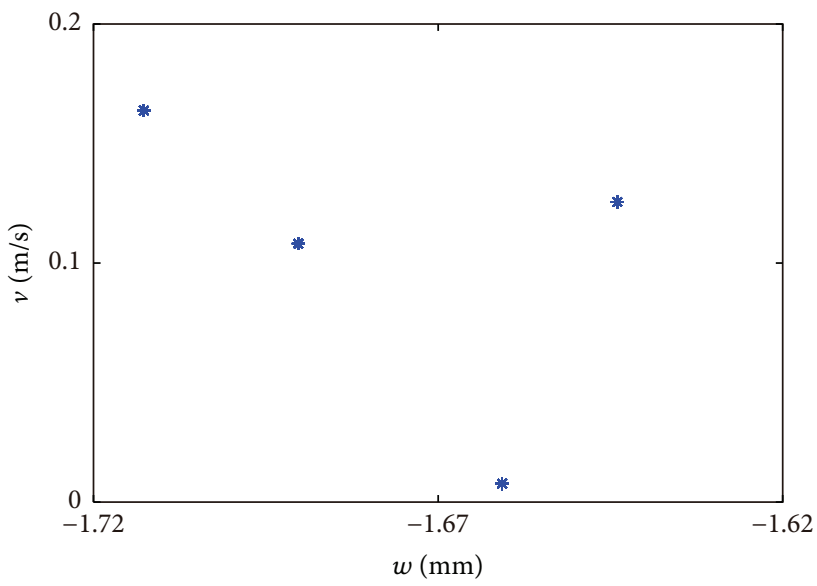

(d) Poincare section

Figure 8: The 4T-periodic motion of cylindrical shell at $\omega=265 \mathrm{~Hz}$.

based on the first-order shear deformation theory [23], the vibrations of various rotating composite laminated structure elements including cylindrical, conical, and spherical shells and annular plates [24], and the vibration of isotropic and orthotropic open shells and plates under general boundary conditions via a unified three-dimensional displacementbased energy formulation [25]. Elastic foundations were also considered by him and his coauthors for the free vibration analysis of thick cylindrical shells with general end conditions based on the three-dimensional theory [26]. Ye et al. [27] discussed the effects of boundary stiffness, subtended angle, and conicity on the frequency parameters of different open shells using Chebyshev polynomials though the RayleighRitz procedure and the method can be developed for cylindrical, conical, or spherical shell. Sun et al. [28] employed the Rayleigh-Ritz method to derive the frequency equations of rotating cylindrical shell with general boundary conditions and the influence of the variations of spring stiffness on the frequencies was illustrated by using the method of the characteristic orthogonal polynomials.

Nonuniform boundary condition, partial support, and point support are also attracting attention. Chen et al. [29] investigated the vibration of cylindrical shell with elastic and nonuniform boundary condition, including varying stiffness boundary condition and point supported and partially supported boundary conditions. Numerical calculation was used to illustrate the effect of different boundary condition on natural frequency using improved Fourier series method and Rayleigh-Ritz method. Singh and Shen [30] analyzed the natural characteristic of open circular cylindrical composite shells with discrete point supports using a variational fullfield method based on the first-order shear deformable theory of shell. Rotary inertia was considered and the displacements of cylindrical shell were defined by using very high-order interpolating polynomials and a large number of preselected nodal points on the reference surface of the shell. And after then, Singh [31] studied the free vibration of open skewed circular cylindrical shells under partial support at the edges. They discussed the effects of different shell parameters on the natural frequency and mode shapes.

It can be seen from the previous literature that most of the researches on cylindrical shell have been limited to linear boundary condition and only little work dealt with dynamic behaviors of cylindrical shell with nonlinear boundary. In 


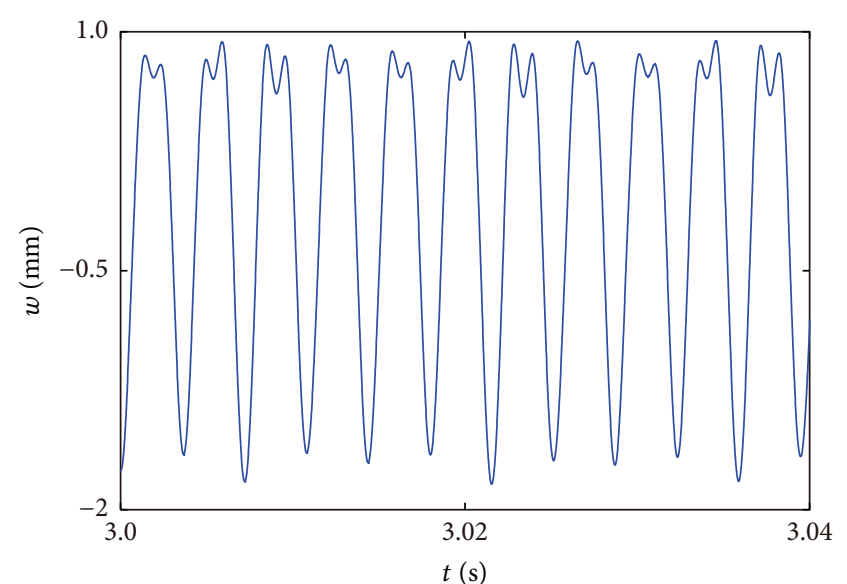

(a) Time history

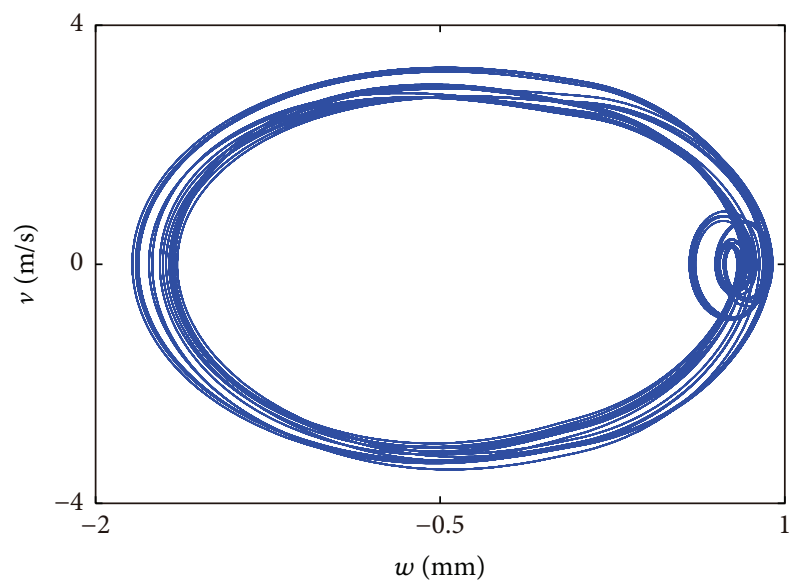

(c) Phase portrait

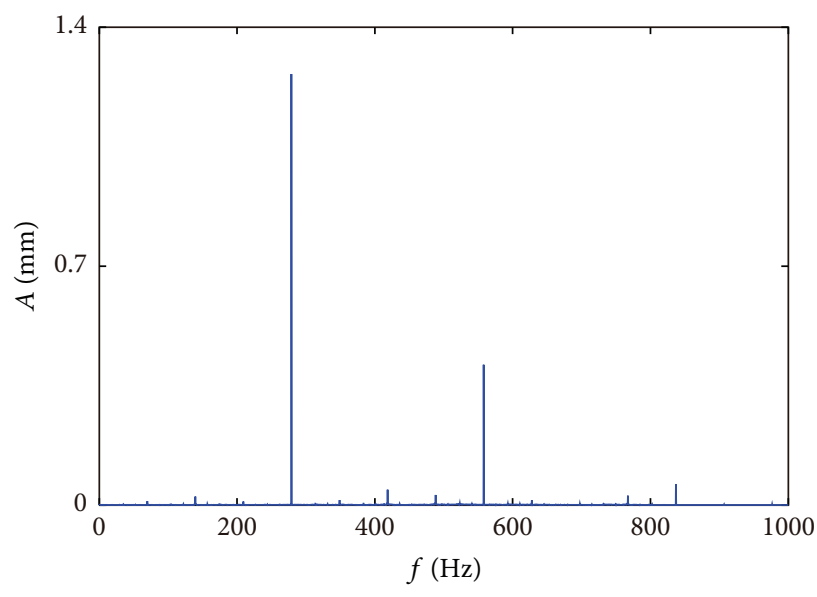

(b) Frequency spectrum plot

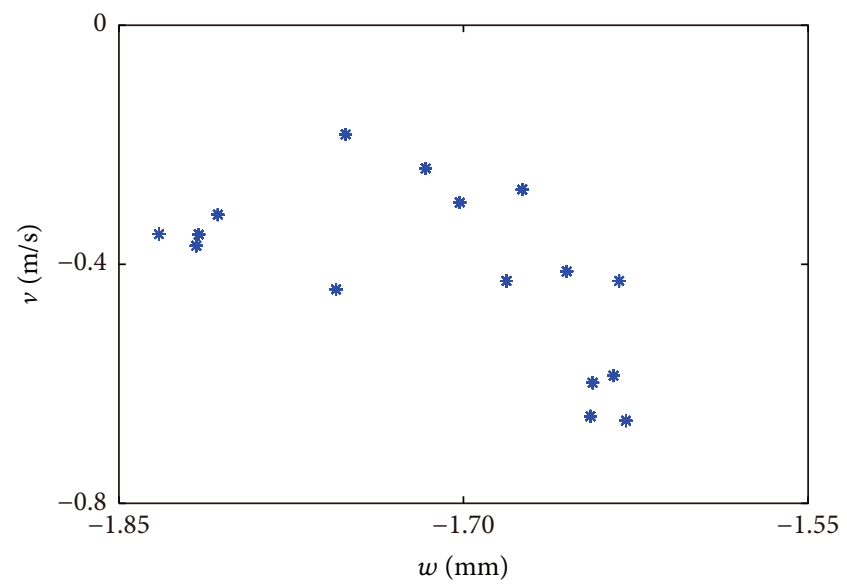

(d) Poincare section

FIGURE 9: The 16T-periodic motion of cylindrical shell at $\omega=279 \mathrm{~Hz}$.

the present paper, we focused our attention on the nonlinear vibration of cylindrical shell under nonlinear boundary condition. Supported clearance in one end was considered. Based on Sanders' theory, Lagrange equations have been written for the nonlinear vibration differential equations. In the analytical formulation, the Rayleigh-Ritz method with a set of displacement shape functions is used to deduce mass, damping, stiffness, and force matrices of the cylindrical shell system. The displacements in three directions are represented by beam function and trigonometric functions. In the study of nonlinear dynamic responses of thin-wall cylindrical shell with supported clearance under external loads, the Newmark method is used to obtain time history, frequency spectrum plot, phase portraits, Poincare section, and bifurcation diagrams with different parameters. The effects of external loads, supported clearance, and support stiffness on nonlinear dynamic behaviors of the system were discussed.

\section{Theory Formulation}

2.1. Simplified System Dynamic Model. Consider a circular cylindrical shell with a supported clearance at the right end and the other end is clamp supported as shown in Figure 1.
A coordinate system $(x, \theta, z)$ is depicted in Figure $1(\mathrm{a})$ in which $x, \theta$, and $z$ are the axial, circumferential, and radial coordinates of the middle surface of the cylindrical shell. The corresponding displacements of an arbitrary point on the middle plane of the cylindrical shell are denoted by $u, v$, and $w$ in $x, \theta$, and $z$ directions, respectively. The geometric parameters of the cylindrical shell are as follows: mean radius $R$, length $L$, and thickness $h$. The material of the cylindrical shell is assumed to be isotropic and mass density is denoted by $\rho$, Young's modulus by $E$, and Poisson's ratio by $\mu$.

Figure 1(b) is the cross-sectional view of the end with clearance. The restraint was assumed to be represented as the springs in radial direction. It is assumed that the springs act in a uniform distributed manner at the ends of the shell and the value of spring stiffness is $k$. However, there is a supported clearance, $b$, between the shell wall and the restraint. Based on this model, it is obvious that if the displacement $w$ of an arbitrary point at the cylindrical shell end was less than the value of $b$, the shell wall would be separated from the corresponding spring and if the displacement $w$ of an arbitrary point at the cylindrical shell end was larger than the value of $b$, the points at the shell end would contact with the corresponding springs. Therefore, the radial restraint stiffness 


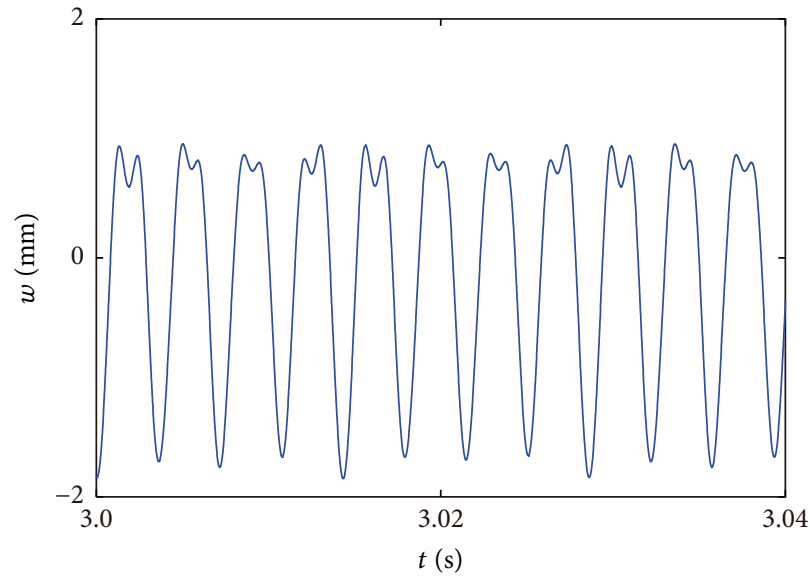

(a) Time history

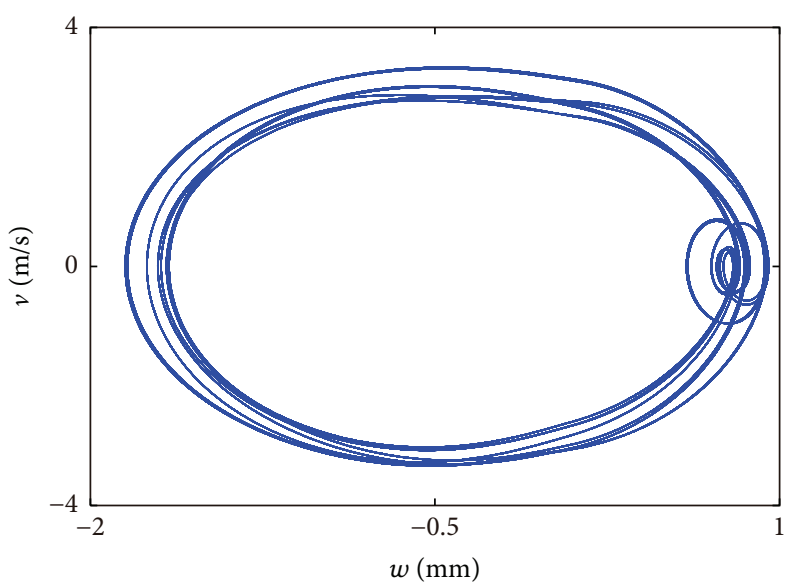

(c) Phase portrait

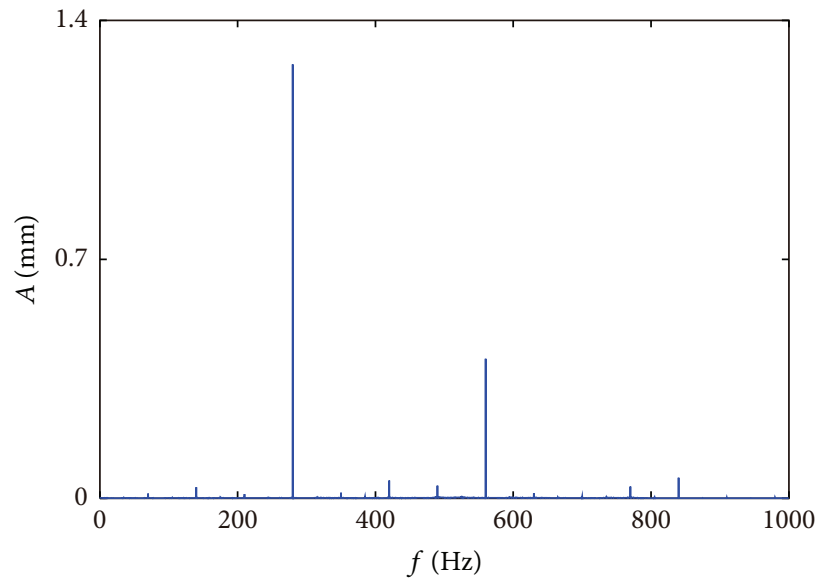

(b) Frequency spectrum plot

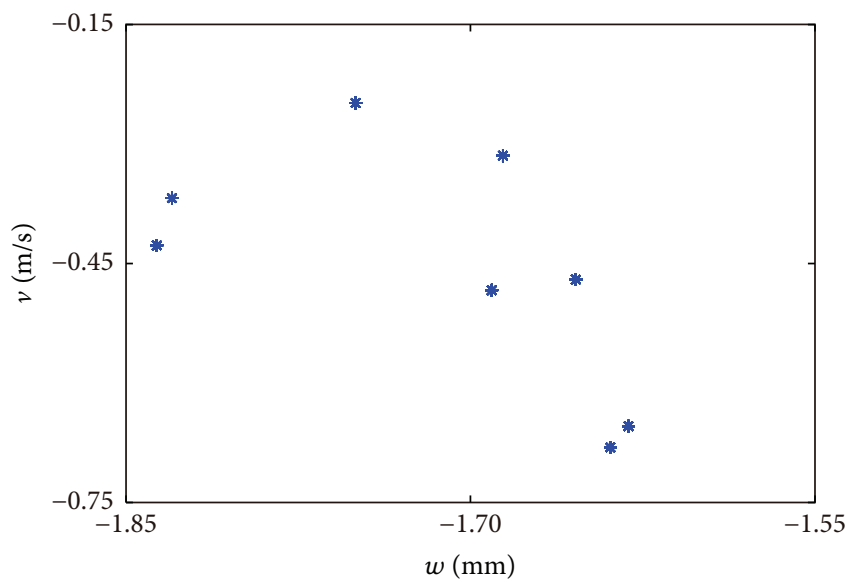

(d) Poincare section

FIGURE 10: The 8T-periodic motion of cylindrical shell at $\omega=280 \mathrm{~Hz}$.

in any point at the right end with supported clearance can be expressed as

$$
k_{w}= \begin{cases}k, & \left.w\right|_{x=L}>b \\ 0, & \left.w\right|_{x=L} \leq b\end{cases}
$$

and the spring forces which represent the restraint forces can be defined as

$$
f_{s w}= \begin{cases}k_{w}\left(\left.w\right|_{x=L}-b\right), & \left.w\right|_{x=L}>b \\ 0, & \left.w\right|_{x=L} \leq b\end{cases}
$$

where $f_{s w}$ are the spring forces in the radial direction.
2.2. Vibration Differential Equation. The kinetic energy for vibration of cylindrical shell is given by

$T$

$$
=\frac{\rho h}{2} \int_{0}^{L} \int_{0}^{2 \pi}\left(\left(\frac{\partial u}{\partial t}\right)^{2}+\left(\frac{\partial v}{\partial t}\right)^{2}+\left(\frac{\partial w}{\partial t}\right)^{2}\right) R \mathrm{~d} x \mathrm{~d} \theta
$$

Based on Sanders' shell theory, the strain energy $U_{\varepsilon}$ for the cylindrical shell is

$$
\begin{aligned}
U_{\varepsilon} & =\int_{0}^{L} \int_{0}^{2 \pi}\left\{\frac{E h}{2\left(1-\mu^{2}\right)}\left[\left(\frac{\partial u}{\partial x}\right)^{2}+\frac{2 \mu}{R} \frac{\partial u}{\partial x}\left(\frac{\partial v}{\partial \theta}+w\right)+\frac{1}{R^{2}}\left(\frac{\partial v}{\partial \theta}+w\right)^{2}+\frac{1-\mu}{2}\left(\frac{1}{R} \frac{\partial u}{\partial \theta}+\frac{\partial v}{\partial x}\right)^{2}\right]\right. \\
& \left.+\frac{E h^{3}}{24\left(1-\mu^{2}\right)}\left[\left(\frac{\partial^{2} w}{\partial x^{2}}\right)^{2}+\frac{2 \mu}{R^{2}} \frac{\partial^{2} w}{\partial x^{2}}\left(\frac{\partial^{2} w}{\partial \theta^{2}}-\frac{\partial v}{\partial \theta}\right)+\frac{1}{R^{4}}\left(\frac{\partial v}{\partial \theta}-\frac{\partial^{2} w}{\partial \theta^{2}}\right)^{2}+\frac{(1-\mu)}{2 R^{2}}\left(\frac{1}{2 R} \frac{\partial u}{\partial \theta}-\frac{3}{2} \frac{\partial v}{\partial x}+2 \frac{\partial^{2} w}{\partial x \partial \theta}\right)^{2}\right]\right\}
\end{aligned}
$$

$\cdot R \mathrm{~d} x \mathrm{~d} \theta$. 


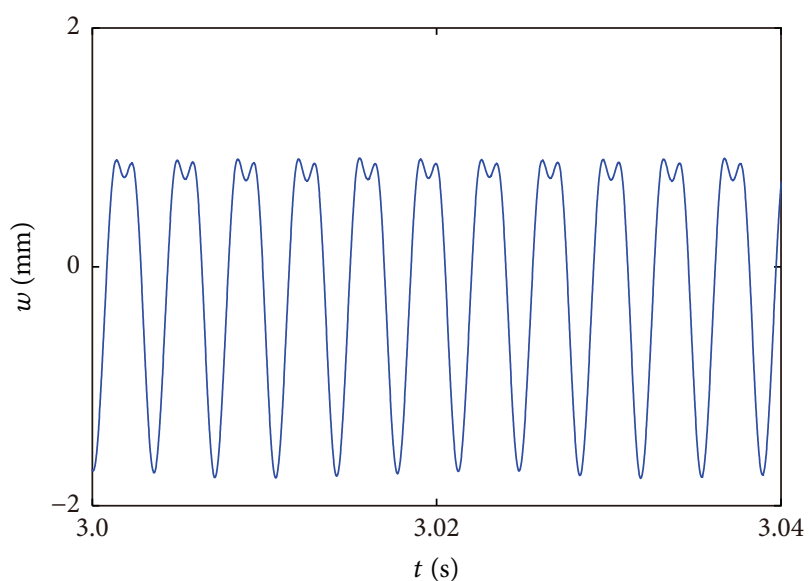

(a) Time history

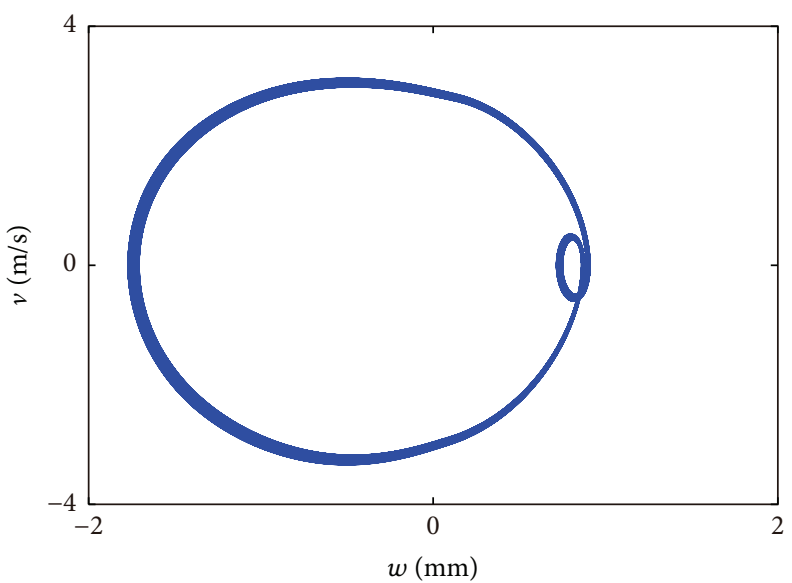

(c) Phase portrait

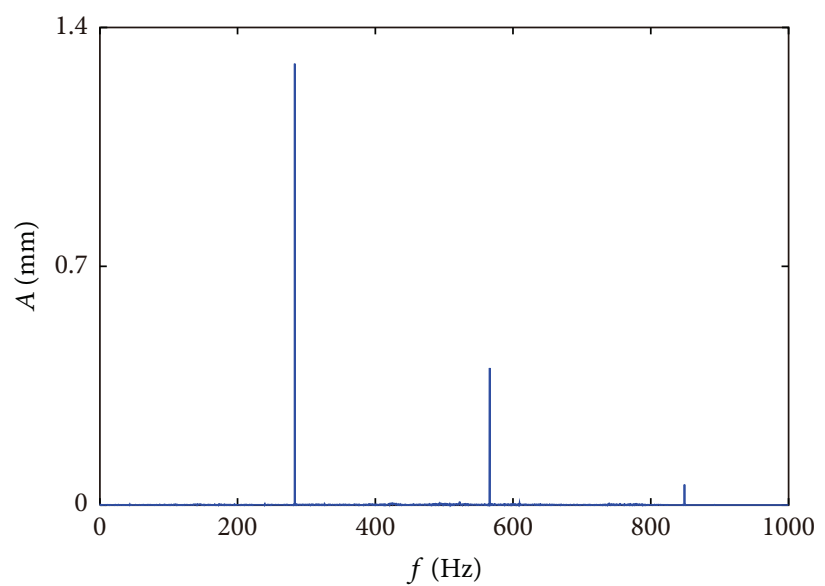

(b) Frequency spectrum plot

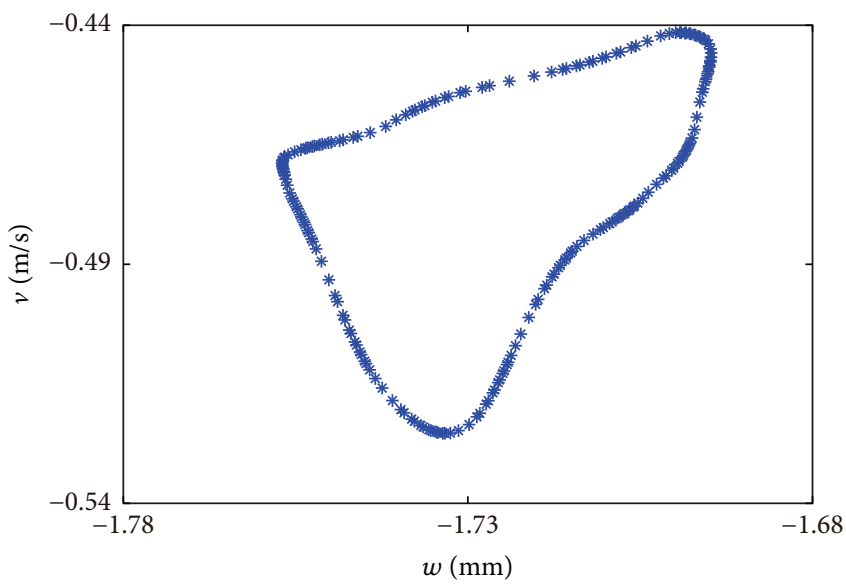

(d) Poincare section

FIGURE 11: The quasiperiodic motion of cylindrical shell at $\omega=283 \mathrm{~Hz}$.

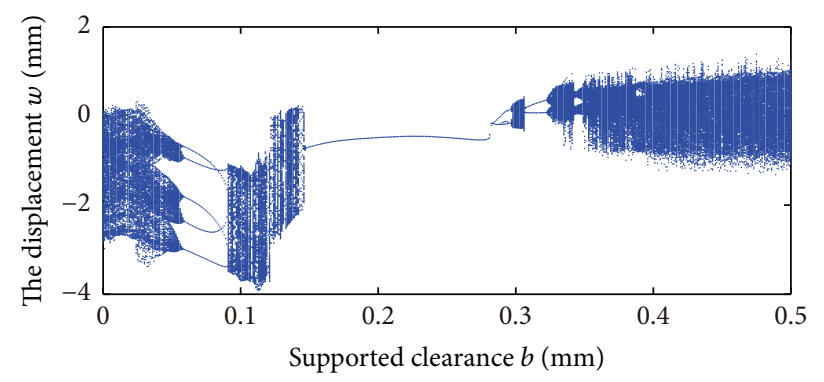

FIGURE 12: The bifurcation diagram of $b$ versus $w$ under $k=5 \times 10^{8} \mathrm{~N} / \mathrm{m}$.

Assuming that the point $Q\left(x=x_{0}, \theta=\theta_{0}\right)$ on the cylindrical shell was suffering from the radial external load, the external load $f_{z}$ was denoted as

$$
f_{z}(x, \theta, t)=F \delta\left(x-x_{0}\right) \delta\left(\theta-\theta_{0}\right) \sin (\omega t),
$$

where $F$ is the amplitude of the external load and $\omega$ is the frequency of the external load. $\delta$ is the Dirac function and one of its properties is

$$
\int_{a}^{b} f(x) \delta(x-c) \mathrm{d} x=f(c), \quad a<c<b .
$$

In order to use the Rayleigh-Ritz method, the displacements $u, v$, and $w$ can be expressed in the terms of generalized coordinates:

$$
\begin{gathered}
u(\xi, \theta, t)=\sum_{i=1}^{m} \sum_{j=1}^{n} A_{i j} U_{i j}(\xi, \theta) \cos (\omega t)=\mathbf{U}^{\mathrm{T}} \mathbf{a}, \\
v(\xi, \theta, t)=\sum_{i=1}^{m} \sum_{j=1}^{n} B_{i j} V_{i j}(\xi, \theta) \cos (\omega t)=\mathbf{V}^{\mathrm{T}} \mathbf{b}, \\
w(\xi, \theta, t)=\sum_{i=1}^{m} \sum_{j=1}^{n} C_{i j} W_{i j}(\xi, \theta) \cos (\omega t)=\mathbf{W}^{\mathrm{T}} \mathbf{c},
\end{gathered}
$$




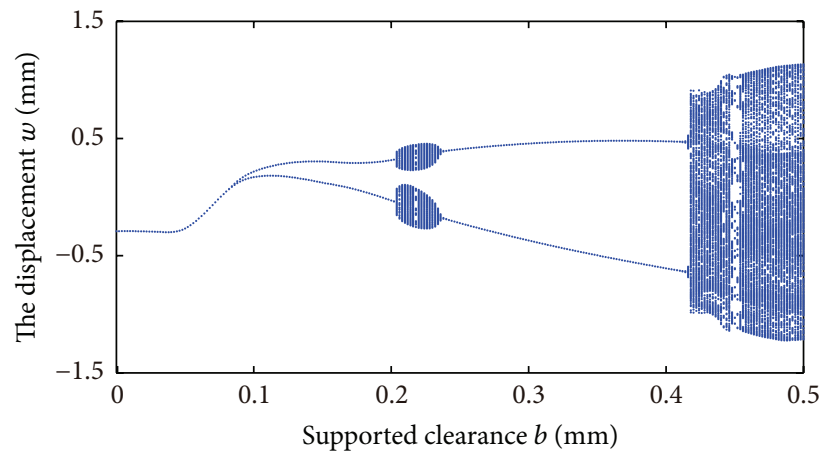

Figure 13: The bifurcation diagram of $b$ versus $w$ under $k=3 \times 10^{8} \mathrm{~N} / \mathrm{m}$.

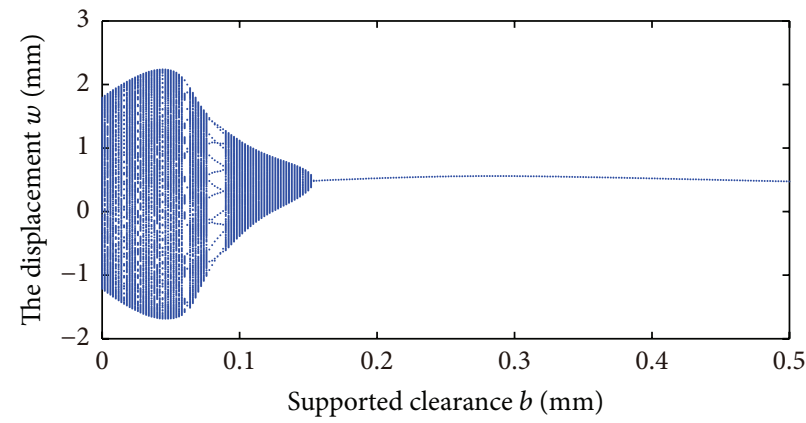

Figure 14: The bifurcation diagram of $b$ versus $w$ under $k=1 \times 10^{8} \mathrm{~N} / \mathrm{m}$.

where $i$ is the number of half waves in axial direction, $j$ is the number of circumference waves, $\mathbf{a}, \mathbf{b}$, and $\mathbf{c}$ are the generalized coordinates, and $\mathbf{U}, \mathbf{V}$, and $\mathbf{W}$ are the principal vibration modes which satisfies the geometric boundary conditions. They are written by

$$
\begin{aligned}
\mathbf{U}= & {\left[U_{11}(\xi, \theta), U_{12}(\xi, \theta), \ldots, U_{i j}(\xi, \theta), \ldots, U_{m n}(\xi, \theta)\right]^{\mathrm{T}} ; } \\
\mathbf{a}= & {\left[A_{11} \cos (\omega t), A_{12} \cos (\omega t), \ldots, A_{i j} \cos (\omega t), \ldots, A_{m n}\right.} \\
& \cdot \cos (\omega t)]^{\mathrm{T}} ; \\
\mathbf{V}= & {\left[V_{11}(\xi, \theta), V_{12}(\xi, \theta), \ldots, V_{i j}(\xi, \theta), \ldots, V_{m n}(\xi, \theta)\right]^{\mathrm{T}} ; } \\
\mathbf{b}= & {\left[B_{11} \cos (\omega t), B_{12} \cos (\omega t), \ldots, B_{i j} \cos (\omega t), \ldots, B_{m n}\right.} \\
& \cdot \cos (\omega t)]^{\mathrm{T}} ; \\
\mathbf{W}= & {\left[W_{11}(\xi, \theta), W_{12}(\xi, \theta), \ldots, W_{i j}(\xi, \theta), \ldots,\right.} \\
& \left.W_{m n}(\xi, \theta)\right]^{\mathrm{T}} ; \\
\mathbf{c}= & {\left[C_{11} \cos (\omega t), C_{12} \cos (\omega t), \ldots, C_{i j} \cos (\omega t), \ldots, C_{m n}\right.} \\
& \cdot \cos (\omega t)]^{\mathrm{T}},
\end{aligned}
$$

where

$$
\begin{aligned}
U_{i j}(\xi, \theta) & =\frac{\partial \varphi_{i}(x)}{\partial(x / L)} \cos (j \theta) ; \\
V_{i j}(\xi, \theta) & =\varphi_{i}(x) \sin (j \theta) ; \\
W_{i j}(\xi, \theta) & =\varphi_{i}(x) \cos (j \theta),
\end{aligned}
$$

where $\varphi_{i}(x)$ is the axial shape function which can be expressed as beam function. The function to be used in this paper is as follows:

$$
\begin{aligned}
\varphi_{i}(x)= & \cosh \left(\frac{\phi_{i} x}{L}\right)-\cos \left(\frac{\phi_{i} x}{L}\right) \\
& -\mu_{i}\left[\sinh \left(\frac{\phi_{i} x}{L}\right)-\sin \left(\frac{\phi_{i} x}{L}\right)\right],
\end{aligned}
$$

where $\phi_{i}, \mu_{i}$ satisfy $\cos \left(\phi_{i}\right) \cosh \left(\phi_{i}\right)=-1$ and $\mu_{i}=\left(\sinh \phi_{i}-\right.$ $\left.\sin \phi_{i}\right) /\left(\cosh \phi_{i}+\cos \phi_{i}\right)$.

Then the kinetic energy, potential energy, and forces can be expressed in terms of the generalized coordinates and displacement shape functions. Substituting (7) into (3), (5), and (2), the generalized potential energy, the generalized exciting force, and the generalized spring force can be gotten:

$$
\begin{aligned}
& T=\frac{1}{2} \dot{\mathbf{a}}^{\mathrm{T}} \mathbf{M}_{1} \dot{\mathbf{a}}+\frac{1}{2} \dot{\mathbf{b}}^{\mathrm{T}} \mathbf{M}_{2} \dot{\mathbf{b}}+\frac{1}{2} \dot{\mathbf{c}}^{\mathrm{T}} \mathbf{M}_{3} \dot{\mathbf{c}}, \\
& U_{\varepsilon} \\
& =\frac{1}{2} \mathbf{a}^{\mathrm{T}} \mathbf{K}_{1} \mathbf{a}+\frac{1}{2} \mathbf{a}^{\mathrm{T}} \mathbf{K}_{2} \mathbf{b}+\frac{1}{2} \mathbf{a}^{\mathrm{T}} \mathbf{K}_{3} \mathbf{c}+\frac{1}{2} \mathbf{b}^{\mathrm{T}} \mathbf{K}_{4} \mathbf{b} \\
& +\frac{1}{2} \mathbf{b}^{\mathrm{T}} \mathbf{K}_{5} \mathbf{c}+\frac{1}{2} \mathbf{c}^{\mathrm{T}} \mathbf{K}_{6} \mathbf{c}, \\
& \mathbf{F}_{f_{z}} \\
& =\int_{0}^{L} \int_{0}^{2 \pi} \mathbf{W F} \sin (\omega t) \delta\left(x-x_{0}\right) \delta\left(\theta-\theta_{0}\right) R \mathrm{~d} \theta \mathrm{d} x,
\end{aligned}
$$




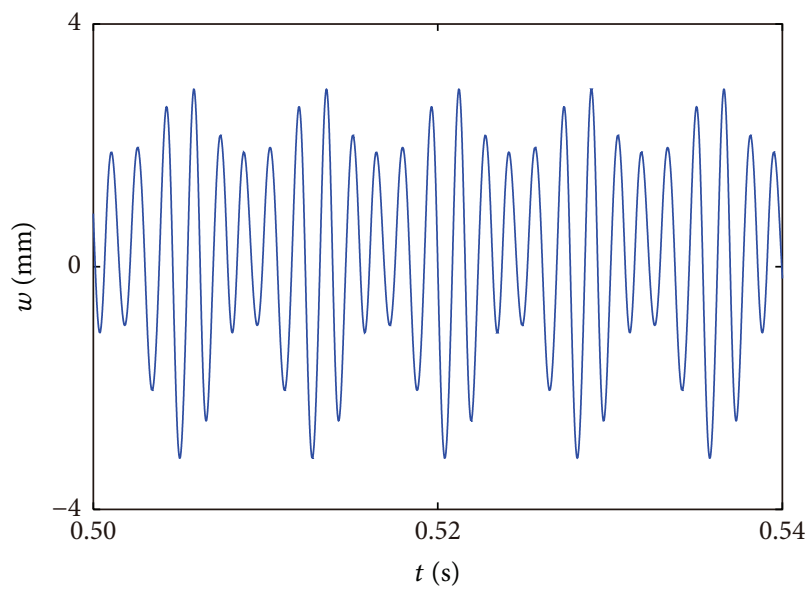

(a) Time history

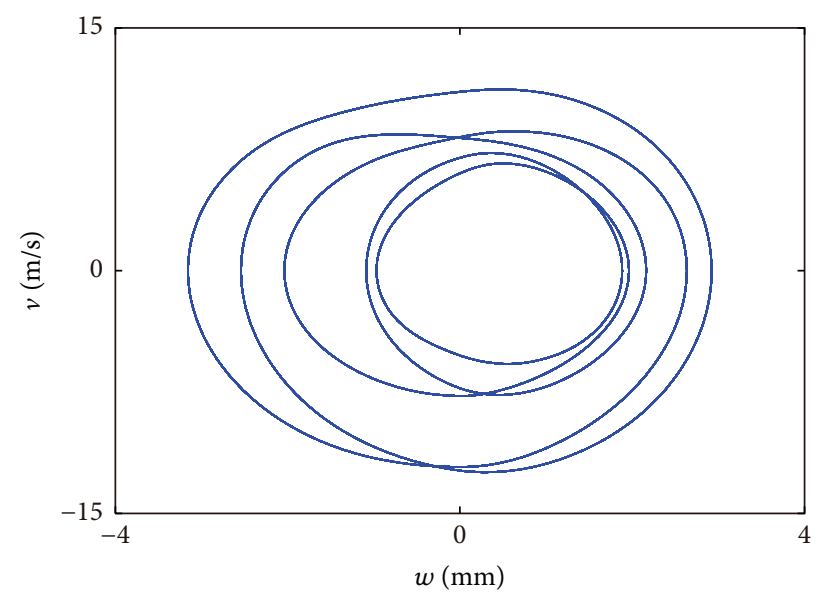

(c) Phase portraits

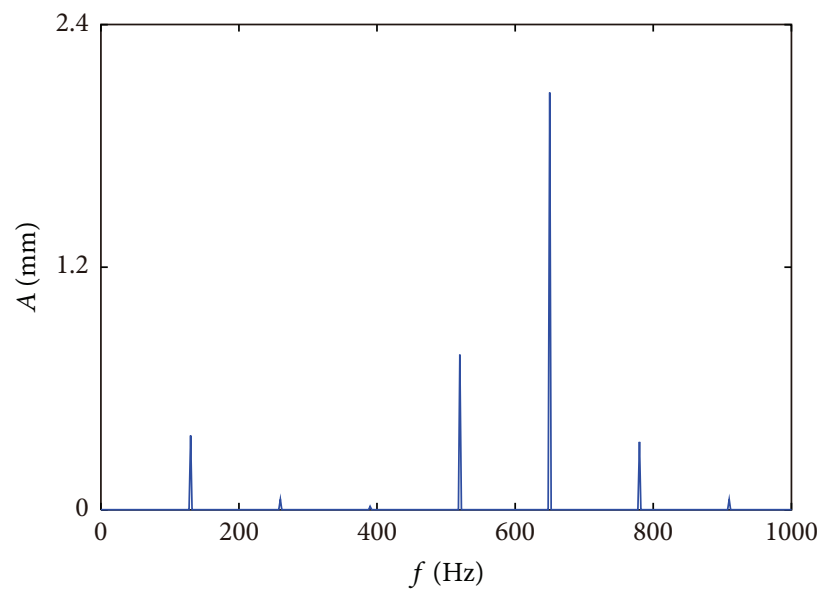

(b) Frequency spectrum plot

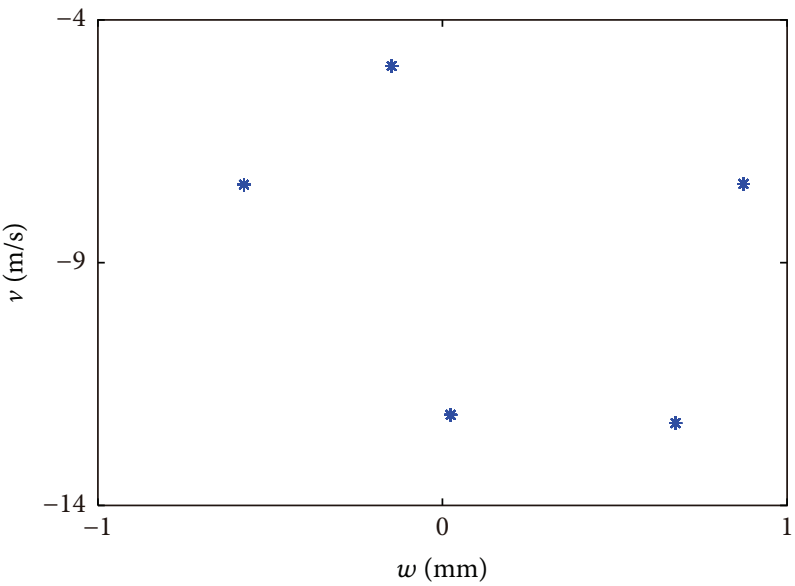

(d) Poincare section

FIGURE 15: The 5T periodic motion of cylindrical shell at $b=0.07 \mathrm{~mm}$.

$$
\begin{aligned}
\mathbf{f}_{s w}(\mathbf{c}) \\
\quad= \begin{cases}\int_{0}^{2 \pi} k_{w} \mathbf{W}_{x=L}\left(\mathbf{W}_{x=L}^{\mathrm{T}} \mathbf{c}-b\right) R \mathrm{~d} \theta, & \mathbf{W}_{x=L}^{\mathrm{T}} \mathbf{c}>b, \\
0, & \mathbf{W}_{x=L}^{\mathrm{T}} \mathbf{c} \leq b,\end{cases}
\end{aligned}
$$

where $\mathbf{M}_{1}, \mathbf{M}_{2}$, and $\mathbf{M}_{3}$ are the modal mass matrices and $\mathbf{K}_{1}$, $\mathbf{K}_{2}, \mathbf{K}_{3}, \mathbf{K}_{4}, \mathbf{K}_{5}$, and $\mathbf{K}_{6}$ are the modal stiffness matrices and they are listed in the Appendix.

Lagrange equation with the Rayleigh-Ritz method will be used to determine the equation of motion of the cylindrical shell. Lagrange equation is written by

$$
\frac{\mathrm{d}}{\mathrm{d} t}\left(\frac{\partial T}{\partial \dot{\mathbf{q}}}\right)-\frac{\partial T}{\partial \mathbf{q}}+\frac{\partial U}{\partial \mathbf{q}}=\mathbf{F}_{f}-\mathbf{F}_{s} .
$$

Substituting (11) into (12), the nonlinear vibration differential equation can be obtained as

$$
\mathbf{M} \ddot{\mathbf{q}}+\mathbf{C} \dot{\mathbf{q}}+\mathbf{K q}+\mathbf{F}_{s}=\mathbf{F}_{f}
$$

where $\mathbf{M}$ and $\mathbf{K}$ are the generalized mass matrix and stiffness matrix. $\mathbf{F}_{s}$ is the spring force vector and $\mathbf{F}_{f}$ is the external force vector:

$$
\begin{aligned}
\mathbf{M} & =\left[\begin{array}{lll}
\mathbf{M}_{1} & & \\
& \mathbf{M}_{2} & \\
& & \mathbf{M}_{3}
\end{array}\right], \\
\mathbf{K} & =\left[\begin{array}{lll}
\mathbf{K}_{1} & \frac{1}{2} \mathbf{K}_{2} & \frac{1}{2} \mathbf{K}_{3} \\
\frac{1}{2} \mathbf{K}_{2}^{\mathrm{T}} & \mathbf{K}_{4} & \frac{1}{2} \mathbf{K}_{5} \\
\frac{1}{2} \mathbf{K}_{3}^{\mathrm{T}} & \frac{1}{2} \mathbf{K}_{5}^{\mathrm{T}} & \mathbf{K}_{6}
\end{array}\right], \\
\mathbf{F}_{s} & =\left[\begin{array}{llll}
\mathbf{0} & \mathbf{0} & \mathbf{f}_{s w}(\mathbf{c})
\end{array}\right]^{\mathrm{T}}, \\
\mathbf{F}_{f} & =\left[\begin{array}{lll}
\mathbf{0} & \mathbf{0} & \mathbf{F}_{f_{z}}
\end{array}\right]^{\mathrm{T}}, \\
\mathbf{q} & =\left[\begin{array}{lll}
\mathbf{a} & \mathbf{b} & \mathbf{c}
\end{array}\right]^{\mathrm{T}} .
\end{aligned}
$$




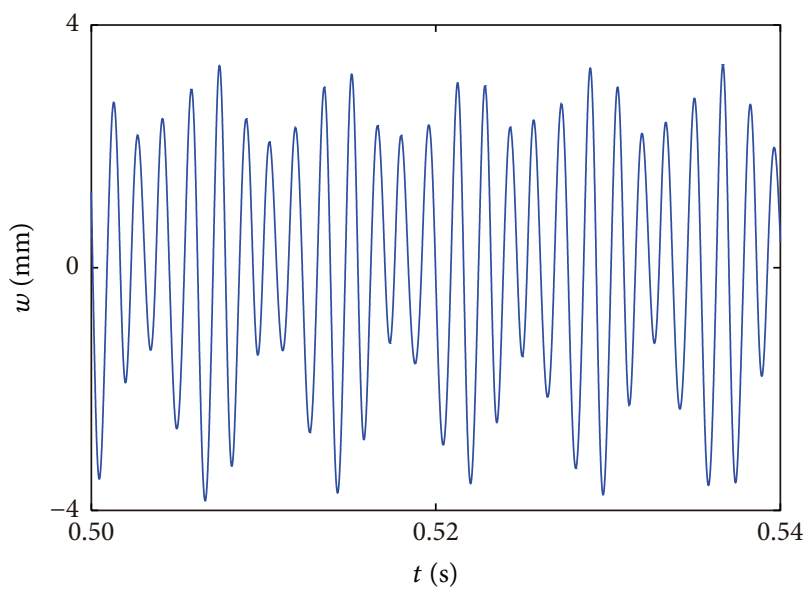

(a) Time history

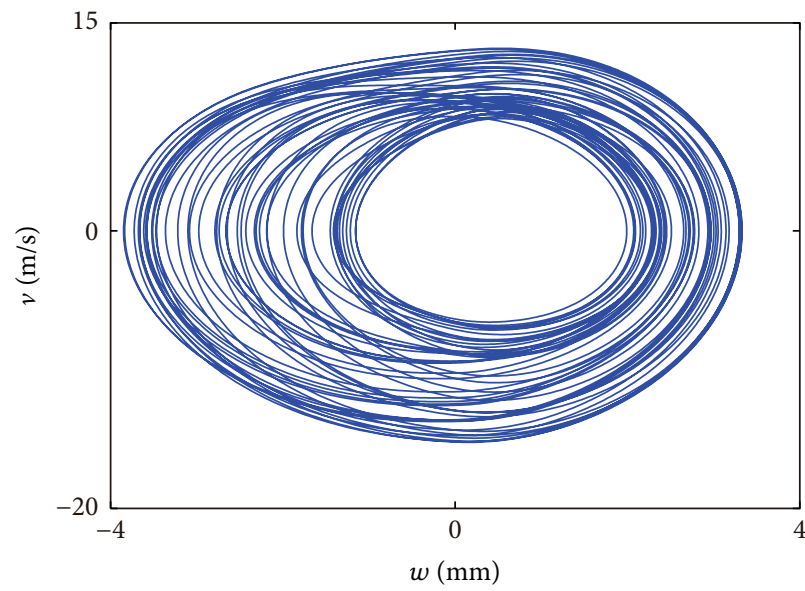

(c) Phase portraits

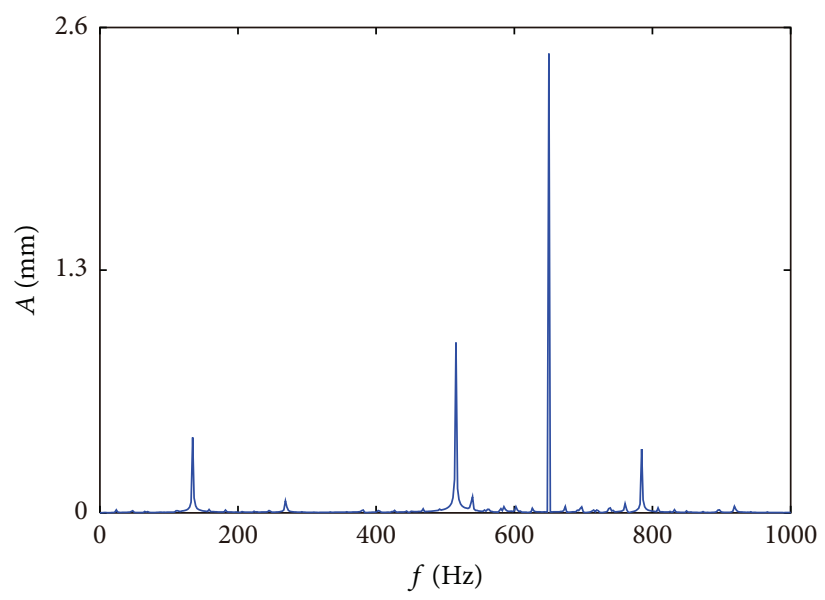

(b) Frequency spectrum plot

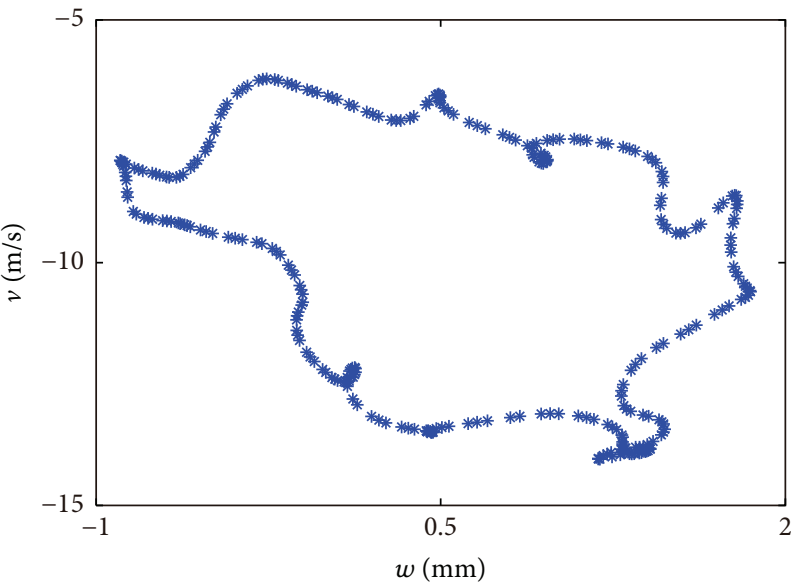

(d) Poincare section

FIGURE 16: The chaotic motion of cylindrical shell at $b=0.1 \mathrm{~mm}$.

TABLE 1: Comparison of values of natural frequency parameter $\Omega=\omega R \sqrt{\rho\left(1-\mu^{2}\right) / E}$ for a circular cylindrical shell with clamped-free boundary condition $\left(m=1, L=0.502 \mathrm{~m}, R=0.0635 \mathrm{~m}, h=0.00163 \mathrm{~m}, \mu=0.28, E=2.1 \times 10^{11} \mathrm{~N} / \mathrm{m}^{2}\right.$, and $\left.\rho=7800 \mathrm{~kg} / \mathrm{m}^{3}\right)$.

\begin{tabular}{|c|c|c|c|c|c|}
\hline \multirow[t]{2}{*}{$n$} & \multicolumn{5}{|c|}{$\Omega=\omega R \sqrt{\rho\left(1-\mu^{2}\right) / E}$} \\
\hline & Present & Ref. [19] & Difference (\%) & Ref. [32] & Difference (\%) \\
\hline 2 & 319.53 & 316.02 & 1.11 & 319.5 & 0.00 \\
\hline 3 & 769.86 & 768.45 & 0.18 & 769.9 & 0.00 \\
\hline 4 & 1465.73 & 1462.8 & 0.20 & 1465.7 & 0.00 \\
\hline 5 & 2366.93 & 2362.2 & 0.20 & 2366.9 & 0.00 \\
\hline
\end{tabular}

And $\mathbf{C}$ is the proportional damping matrix and can be expressed as $\mathbf{C}=\alpha \mathbf{M}+\beta \mathbf{K}$. Assuming that the proportional damping constant is $\xi$ and $\omega_{n}$ is the natural frequency, $\alpha$ and $\beta$ are given as $\alpha / 2 \omega_{n}+\beta \omega_{n} / 2=\xi$.

\section{Results and Discussion}

3.1. Verification of the Accuracy and Reliability. To verify the accuracy and reliability of the present method, comparisons are made with available values in open literature through a numerical example under the boundary condition without clearance. According to the vibration equation (13), only when $k=0$, the equation is a linear equation. The case for $k=$ 0 represents clamped-free supported boundary conditions. So the frequency parameters under $k=0$ were compared with the results in open literatures $[19,32]$ and they had been listed in Table 1. The frequency parameters in [19] were obtained by modified Fourier method based on Love's shell theory. Those in [32] were obtained based on Sanders' theory. Excellent agreement for frequency parameters of cylindrical shells is achieved. Therefore, the present analysis of the modal and method used in this paper is accurate and credible and 


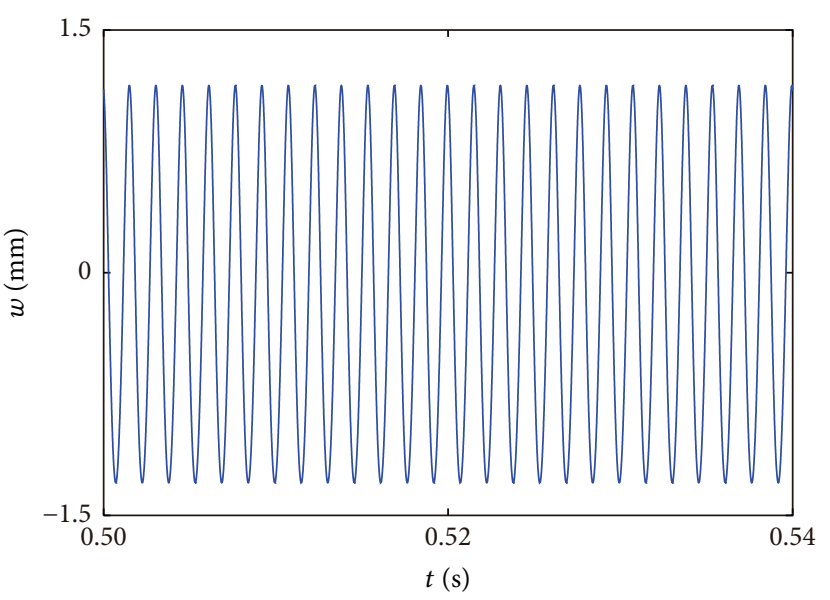

(a) Time history

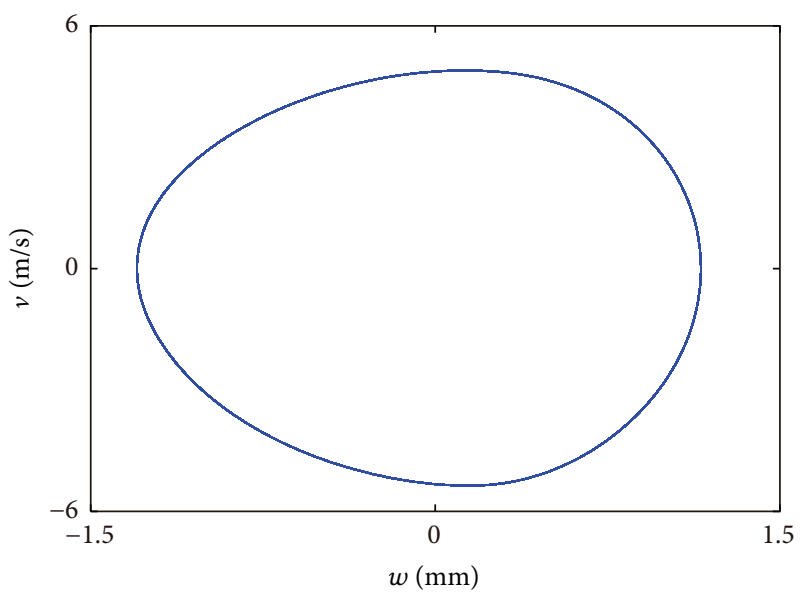

(c) Phase portraits

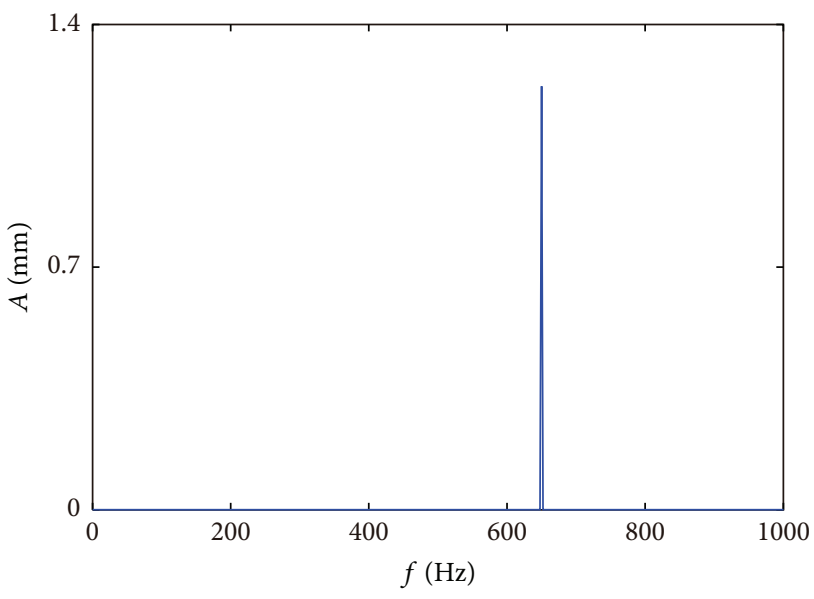

(b) Frequency spectrum plot

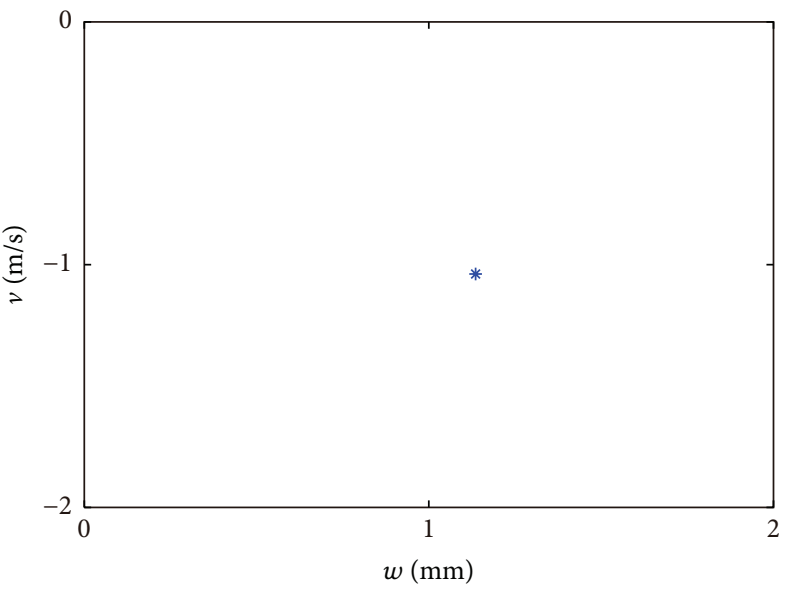

(d) Poincare section

FIGURE 17: The periodic motion of cylindrical shell at $b=0.2 \mathrm{~mm}$.

provides the theoretical basis for the following simulating and calculation.

\subsection{Effect of Load Frequency on Dynamic Characteristic} of Cylindrical Shell. The nonlinear differential equation for cylindrical shell could exhibit complex dynamic characteristics. In order to study the complexity of vibration, the bifurcation diagrams, time histories, frequency spectrum plots, phase portraits, and Poincare sections are selected as tools to study the nonlinear dynamic responses of the cylindrical shell. A numerical analysis is performed in this paper by considering the Newmark method on the cylindrical shell with supported clearance at one end. All the geometric parameters and material parameters of the shell are as follows: $L=1 \mathrm{~m}, h=0.01 \mathrm{~m}, R=0.5 \mathrm{~m}, \mu=0.3, \rho=$ $7850 \mathrm{~kg} / \mathrm{m}^{3}$, and $E=2.06 \times 10^{11} \mathrm{~Pa}$. The load frequency was controlled in the range from $150 \mathrm{~Hz}$ to $750 \mathrm{~Hz}$. In following calculation, according to the small length to radius radio, one fundamental longitudinal mode was considered here. And considering the natural frequencies of the modes in the range of the load frequency band, circumferential number $n$ was set to eight.
Due to the existence of supported clearance, the system is a nonlinear vibration system, and the dynamic behaviors of this system are very sensitive to the external load frequency. In this part, external load frequency was firstly selected as the controlling parameter to investigate the responses of the cylindrical shell.

When the support stiffness $k=3 \times 10^{8} \mathrm{~N} / \mathrm{m}$, Figures 2, 3, and 4 depict the bifurcation of the external load frequency versus the radial displacement with the frequency of the external load from $150 \mathrm{~Hz}$ to $750 \mathrm{~Hz}$ under the supported clearance $b=0.1 \mathrm{~mm}, b=0.2 \mathrm{~mm}$, and $b=0.3 \mathrm{~mm}$, respectively. Comparing with dynamic phenomena in these figures, various vibrating modes exist under a supported clearance at one end of the cylindrical shell and we can also conclude that under different clearances, the sensibilities of the vibrating mode on load frequency are different. For concision, the dynamic behavior at $b=0.1 \mathrm{~mm}$ is discussed as an example. The same method can be applied for the dynamic behaviors at other supported clearance values.

From Figure 2, it is obvious that the nonlinear dynamic responses are complex when the load frequency increases from $150 \mathrm{~Hz}$ to $750 \mathrm{~Hz}$. There are many sensitive intervals of 


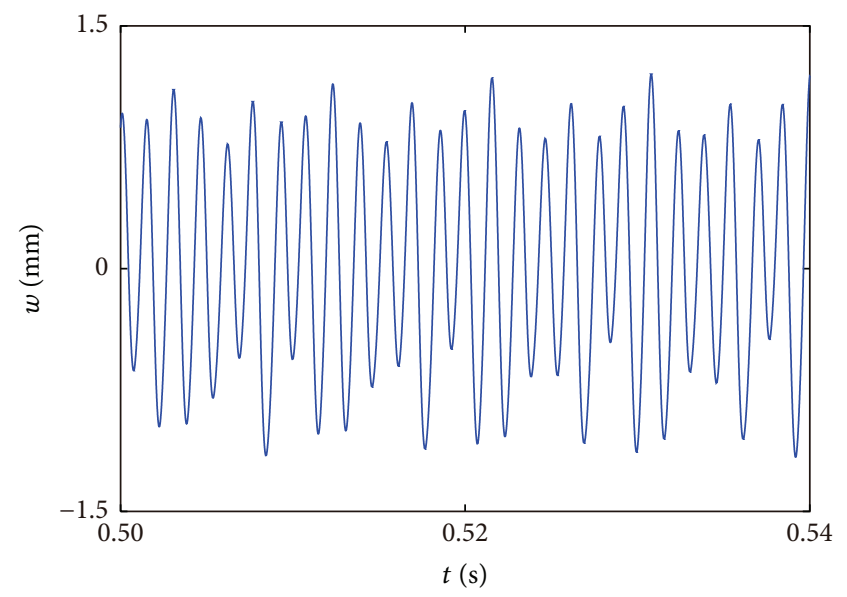

(a) Time history

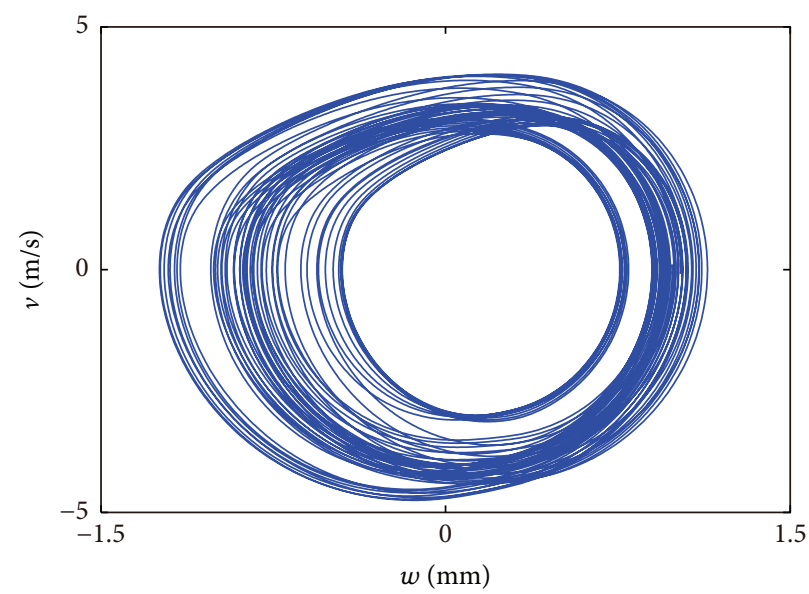

(c) Phase portraits

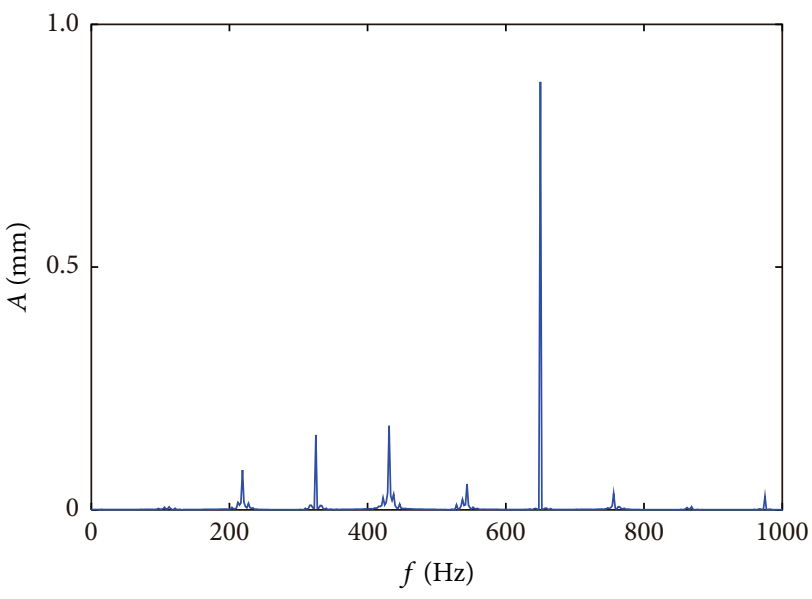

(b) Frequency spectrum plot

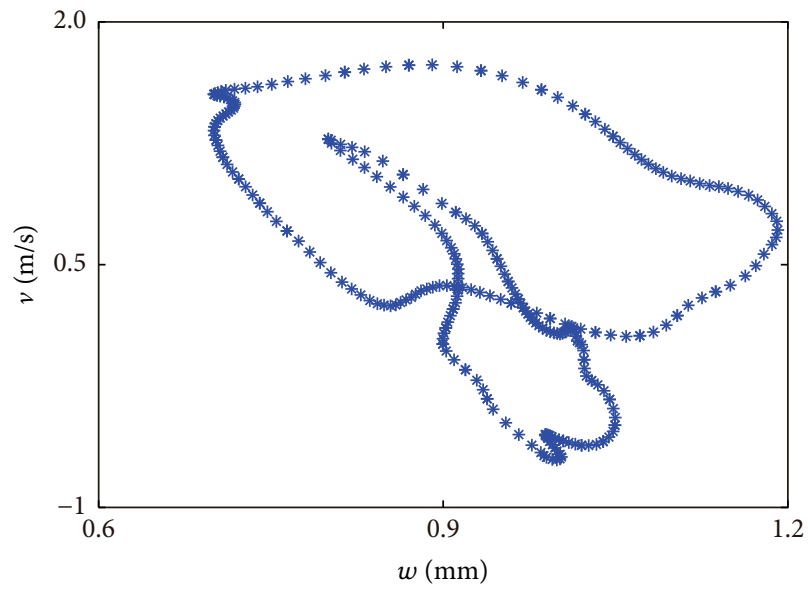

(d) Poincare section

FIGURE 18: The chaotic motion of cylindrical shell at $b=0.3 \mathrm{~mm}$.

load frequency in which the dynamic responses are sensitive to the variation of load frequency. To clearly discuss the dynamic phenomenon of the cylindrical shell, the sensitive interval $260 \mathrm{~Hz} \leqslant \omega \leqslant 295 \mathrm{~Hz}$ is analyzed as an example. Figure 5 shows the local bifurcation in which the load frequency step is $0.1 \mathrm{~Hz}$ and the three-dimensional spectrum in which the load frequency step is $0.5 \mathrm{~Hz}$. It is obvious that the dynamic behaviors periodic motion, multiperiodic motion, quasiperiodic motion, and even chaotic motion emerge alternately in the range of load frequency from $260 \mathrm{~Hz}$ to $295 \mathrm{~Hz}$. As shown in Figures 5(a) and 5(b), when the load frequency is lower than $261.9 \mathrm{~Hz}$, it is periodic motion with the frequencies $\omega, 2 \omega$, and $3 \omega$ in the threedimensional spectrum plot. In $262 \mathrm{~Hz} \leqslant \omega \leqslant 264.2 \mathrm{~Hz}$, it may be quasiperiodic motion or chaotic motion with many frequencies of little amplitudes in the three-dimensional spectrum plot. At the load frequency $\omega=264.3 \mathrm{~Hz}$, the response under a period-doubling bifurcation resulting in 4T-periodic motion in the bifurcation diagram and $1 / 2$ and $1 / 4$ subharmonic frequency gradually emerge in the threedimensional spectrum plot. And the 4T-periodic motion is maintained in the range of load frequency from $264.3 \mathrm{~Hz}$ to
$270.5 \mathrm{~Hz}$ and the range from $273.2 \mathrm{~Hz}$ to $276.1 \mathrm{~Hz}$. Similarly, 8T-period-doubling bifurcation emerges in the range from $276.2 \mathrm{~Hz}$ to $276.8 \mathrm{~Hz}$ and in the range from $279.92 \mathrm{~Hz}$ to $280.5 \mathrm{~Hz}$ and 16T-period-doubling bifurcation appears in the range from $276.8 \mathrm{~Hz}$ to $277.2 \mathrm{~Hz}$ and in the range from $278.5 \mathrm{~Hz}$ to $279.8 \mathrm{~Hz}$. These maybe resulted in the many subharmonic frequencies in the three-dimensional spectrum plot, such as $1 / 8 \omega, 1 / 4 \omega, 1 / 2 \omega$, and $3 / 4 \omega$. In the sensitive interval like $285.4 \mathrm{~Hz} \leqslant \omega \leqslant 291.2 \mathrm{~Hz}$, the response may be chaotic motion according to the random frequencies in the three-dimensional spectrum plot. Other intervals can be analyzed by the same method.

To accurately identify the dynamic behaviors of cylindrical shell, the time histories, frequency spectrum plots, phase portraits, and Poincare section are plotted at several given load frequencies in Figures 6, 7, 8, 9, 10, and 11, respectively. When $\omega=260 \mathrm{~Hz}$, as shown in Figure 6, the only point in Poincare section suggests that the response is a periodic motion. Figure 7 exhibits the time history, frequency spectrum plot, phase portrait, and Poincare section of chaotic motion of the system at $\omega=263 \mathrm{~Hz}$. As shown in Figures 8, 9, and 10, the isolated 4 points, 16 points, and 


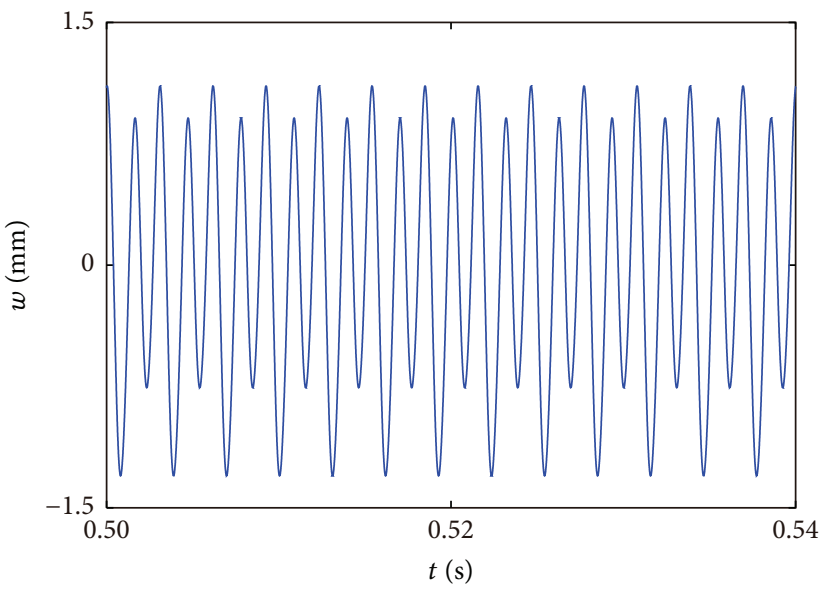

(a) Time history

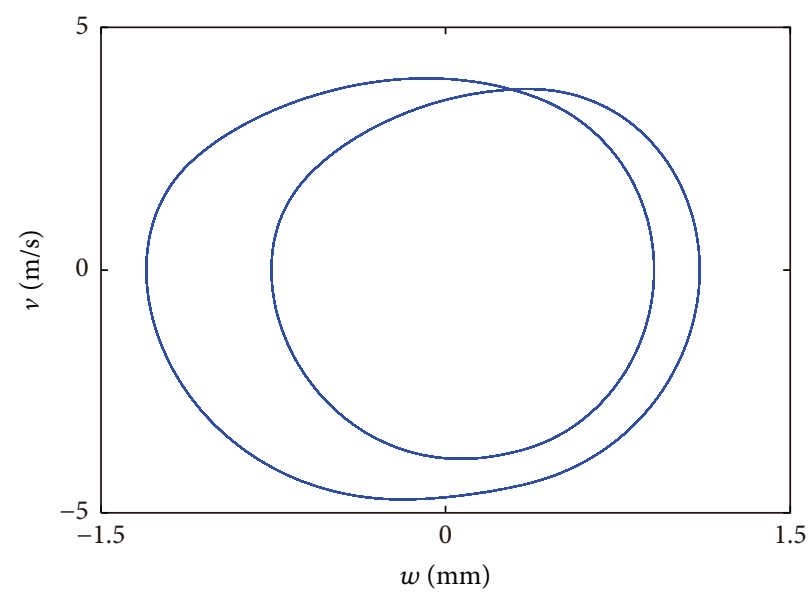

(c) Phase portraits

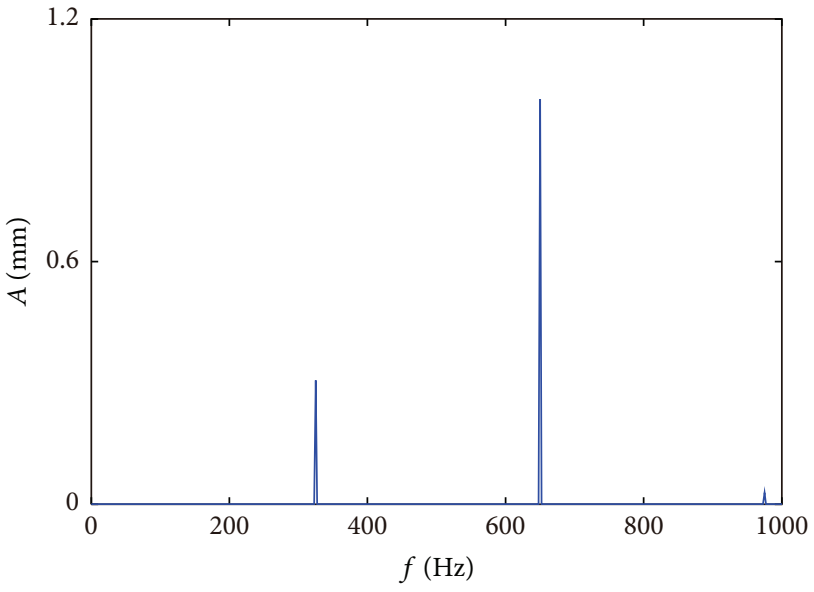

(b) Frequency spectrum plot

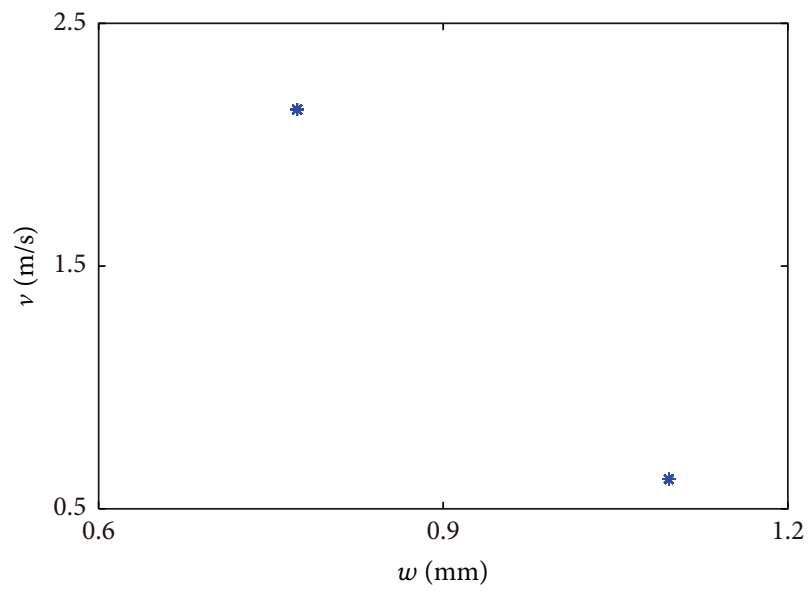

(d) Poincare section

Figure 19: The 2T-periodic motion of cylindrical shell at $b=0.32 \mathrm{~mm}$.

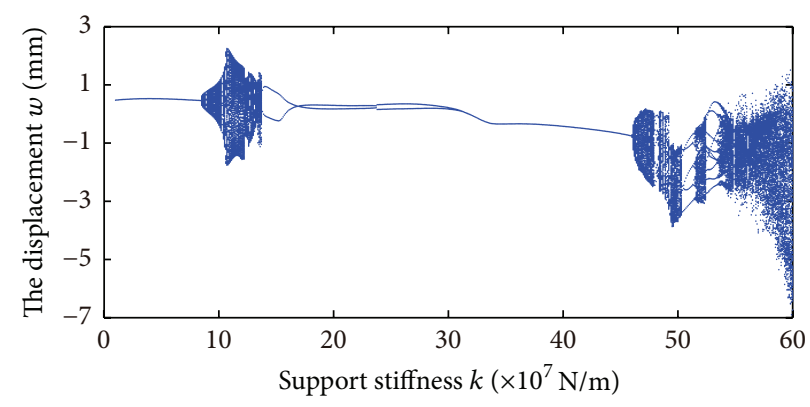

FIgURE 20: The bifurcation diagram of $k$ versus $w$ under $b=0.1 \mathrm{~mm}$ and $\omega=650 \mathrm{~Hz}$.

8 points in the Poincare sections indicate that the responses of the cylindrical shell are 4T-periodic motion, 16T-periodic motion, and 8T-periodic motion at $\omega=265 \mathrm{~Hz}, \omega=279 \mathrm{~Hz}$, and $\omega=280 \mathrm{~Hz}$, respectively. When $\omega=283 \mathrm{~Hz}$, in Figure 11, the time history and the phase portraits are irregular; the Poincare section consists of a large number of points lying on a closed curve. These phenomena all suggest that the response is a quasiperiodic motion.

3.3. Effect of Supported Clearance on Dynamic Characteristic of Cylindrical Shell. From (13), supported clearance is the main reason why the dynamic responses of cylindrical shell show nonlinearity in this paper. And from Figures 2, 3 , and 4 , we can get a summary conclusion that supported clearance has a great influence on dynamic characteristic of cylindrical shell. So we choose the supported clearance as the controlling parameter to study the bifurcation diagram of supported clearance versus the displacement of the wall of cylindrical shell in the radial direction when the support stiffness is set to be $k=5 \times 10^{8} \mathrm{~N} / \mathrm{m}, k=3 \times 10^{8} \mathrm{~N} / \mathrm{m}$, $k=1 \times 10^{8} \mathrm{~N} / \mathrm{m}$, and $k=5 \times 10^{7} \mathrm{~N} / \mathrm{m}$ as shown in Figures 12,13 , and 14 , respectively. It is obvious that the great 


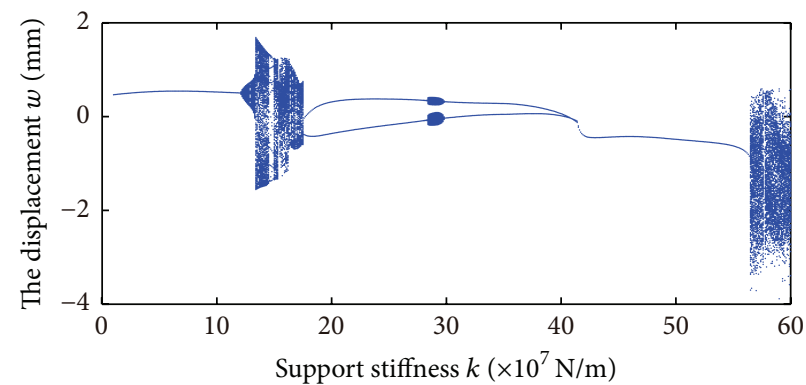

Figure 21: The bifurcation diagram of $k$ versus $w$ under $b=0.2 \mathrm{~mm}$ and $\omega=650 \mathrm{~Hz}$.

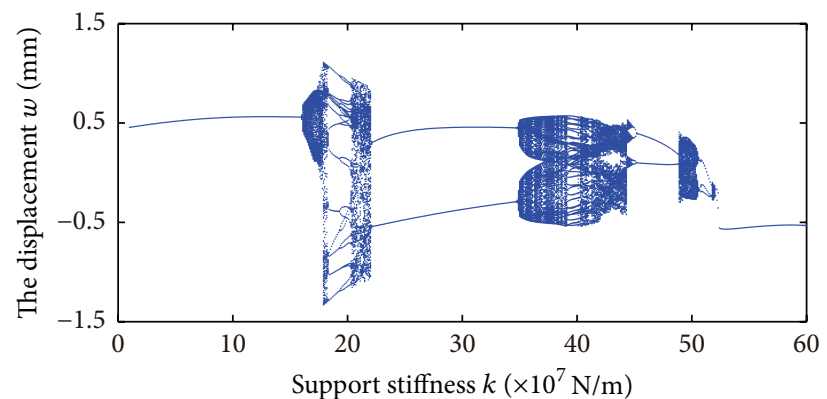

FIgURE 22: The bifurcation diagram of $k$ versus $w$ under $b=0.3 \mathrm{~mm}$ and $\omega=650 \mathrm{~Hz}$.

difference of the bifurcation phenomenon of $b$ versus $w$ exists among different values of support stiffness. Under $k=5 \times$ $10^{8} \mathrm{~N} / \mathrm{m}$, the sensitive intervals of supported clearance are $0 \mathrm{~mm} \leqslant b \leqslant 0.15 \mathrm{~mm}$ and $0.28 \leqslant b \leqslant 0.5 \mathrm{~mm}$ and the sensitive intervals under $k=3 \times 10^{8} \mathrm{~N} / \mathrm{m}$ are $0.2 \mathrm{~mm} \leqslant$ $b \leqslant 0.24 \mathrm{~mm}$ and $0.41 \leqslant b \leqslant 0.5 \mathrm{~mm}$. However, the sensitive interval under $k=1 \times 10^{8} \mathrm{~N} / \mathrm{m}$ is only in the range of $0 \mathrm{~mm} \leqslant b \leqslant 0.156 \mathrm{~mm}$. These all indicate that supported clearance has a great impact on dynamic behavior of cylindrical shell and stiffness value affects the sensitivity of supported clearance on dynamic response. As an example, the dynamic behaviors of cylindrical shell at $k=5 \times 10^{8} \mathrm{~N} / \mathrm{m}$ are analyzed. Figure 12 shows the bifurcation phenomenon when the supported clearance $b$ is increased from $0 \mathrm{~mm}$ to $0.5 \mathrm{~mm}$ under $k=5 \times 10^{8} \mathrm{~N} / \mathrm{m}$.

Scanning from left to right, the response is a chaos motion firstly. When the supported clearance increases from $0.059 \mathrm{~mm}$ to $0.09 \mathrm{~mm}$, it is a $5 \mathrm{~T}$-periodic motion. A periodic motion is maintained in the range of supported clearance from $0.148 \mathrm{~mm}$ to $0.28 \mathrm{~mm}$. In the range of the clearance from $b=0.282 \mathrm{~mm}$ to $0.289 \mathrm{~mm}$, from $0.295 \mathrm{~mm}$ to $0.296 \mathrm{~mm}$, and from $0.307 \mathrm{~mm}$ to $0.322 \mathrm{~mm}$, the response undergoes a period-doubling bifurcation resulting in $2 \mathrm{~T}$-periodic motion in the bifurcation diagram. And it is $3 \mathrm{~T}$-periodic motion in a little range $0.289 \mathrm{~mm}<b<0.295 \mathrm{~mm}$. The responses become chaotic motion in the range between $0.322 \mathrm{~mm}$ and $0.5 \mathrm{~mm}$.

To detect the motion state of cylindrical shell such as periodic motion, multiperiodic motion, quasiperiodic motion, or chaotic motion deduced in the bifurcation diagram, the plots of time history, frequency spectrum plot, phase portraits, and Poincare section under some chosen supported clearances were presented in Figures 15, 16, 17, 18, and 19. Figure 15 illustrates the response of the 5T-periodic motion of this system at $b=0.07 \mathrm{~mm}$. The 5 isolated points in the Poincare section confirm that the response is indeed 5T-periodic motion. As same as this phenomenon, the periodic motion appears at $b=$ $0.2 \mathrm{~mm}$ and the 2T-periodic motion emerges at $b=0.32 \mathrm{~mm}$ as seen from Figures 17 and 19. As shown in Figures 16 and 18, the time history, phase portraits, and Poincare section are so irregular that it can be deduced that the responses are chaotic motions.

3.4. Effect of Support Stiffness on Dynamic Characteristic of Cylindrical Shell. From Figures 12, 13, and 14, it can be seen that support stiffness $k$ is also an important factor on dynamic response of cylindrical shell. So we consider the support stiffness as the bifurcation parameter to study the dynamic response of cylindrical shell under nonlinear boundary with supported clearance $b=0.1 \mathrm{~mm}, b=0.2 \mathrm{~mm}$, and $b=$ $0.3 \mathrm{~mm}$ in Figures 20, 21, and 22, respectively. Again these three figures illustrate supported clearance effects dynamic behaviors of cylindrical shell and the value of clearance affects the sensitivity of support stiffness on dynamic response. As shown, Figure 20 depicts the bifurcation of support stiffness versus the radial displacement with the support stiffness $k$ from $k=1 \times 10^{7} \mathrm{~N} / \mathrm{m}$ to $k=6 \times 10^{8} \mathrm{~N} / \mathrm{m}$ under $b=$ $0.1 \mathrm{~mm}$ and $\omega=650 \mathrm{~Hz}$. It is obvious that the support stiffness affects the dynamic response of cylindrical shell, especially in some sensitive intervals such as $8 \times 10^{7} \mathrm{~N} / \mathrm{m} \leqslant$ $k \leqslant 1.5 \times 10^{8} \mathrm{~N} / \mathrm{m}$ and $4.5 \times 10^{8} \mathrm{~N} / \mathrm{m} \leqslant k \leqslant 6 \times$ $10^{8} \mathrm{~N} / \mathrm{m}$ in Figure 20. As an example, the sensitive interval $4.5 \times 10^{8} \mathrm{~N} / \mathrm{m} \leqslant k \leqslant 5.5 \times 10^{8} \mathrm{~N} / \mathrm{m}$ is discussed in detail. 


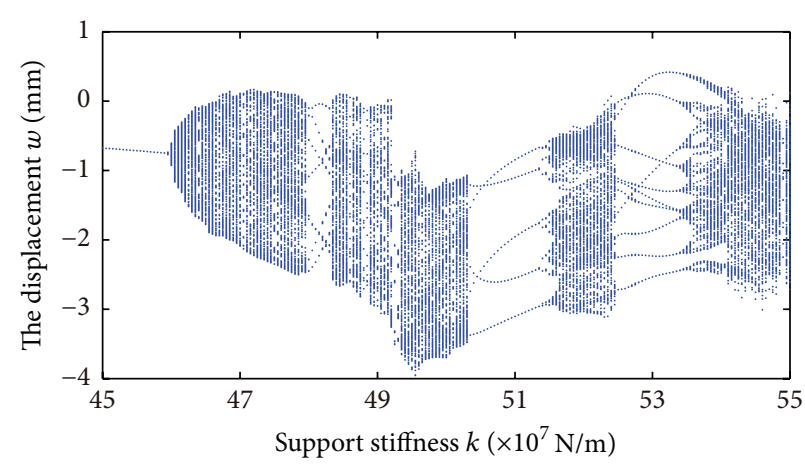

(a) The local bifurcation diagram

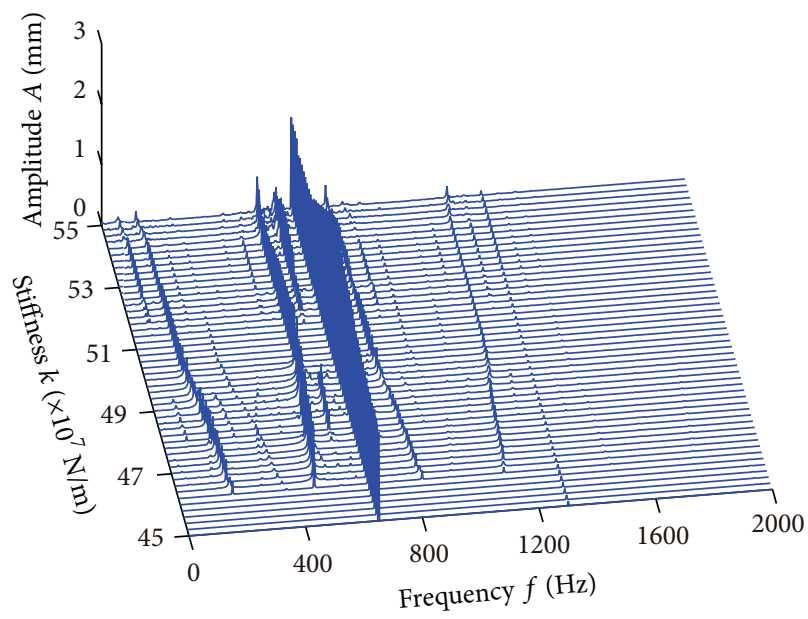

(b) The three-dimensional spectrum plot

FIGURE 23: The local bifurcation diagram and the three-dimensional spectrum plot when $4.5 \times 10^{8} \mathrm{~N} / \mathrm{m} \leqslant k \leqslant 5.5 \times 10^{8} \mathrm{~N} / \mathrm{m}$.

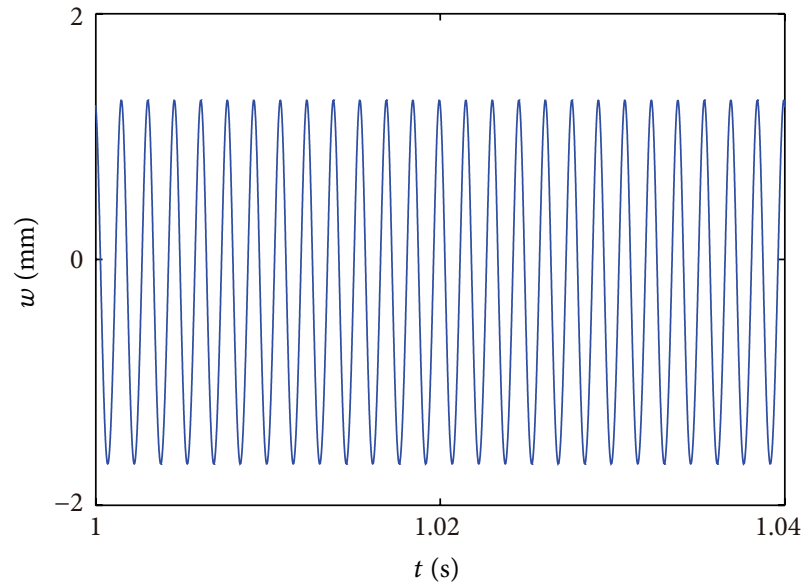

(a) Time history

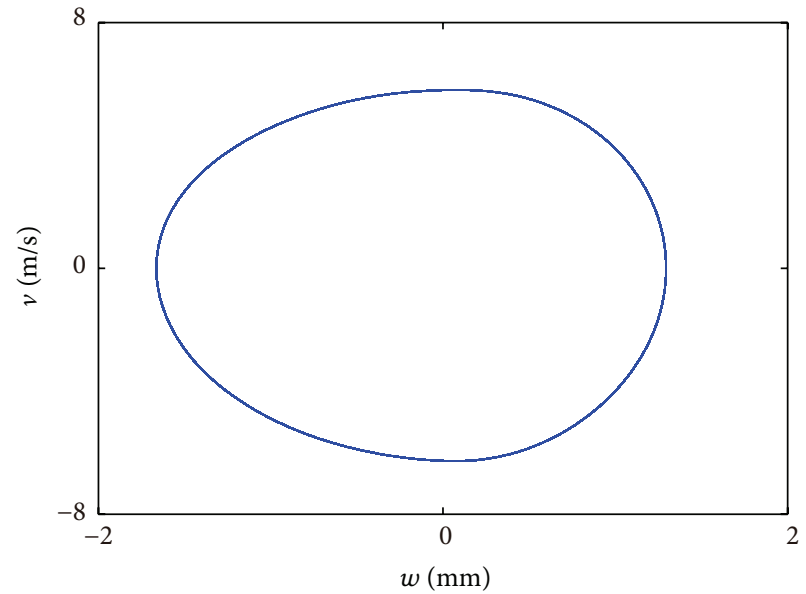

(c) Phase portraits

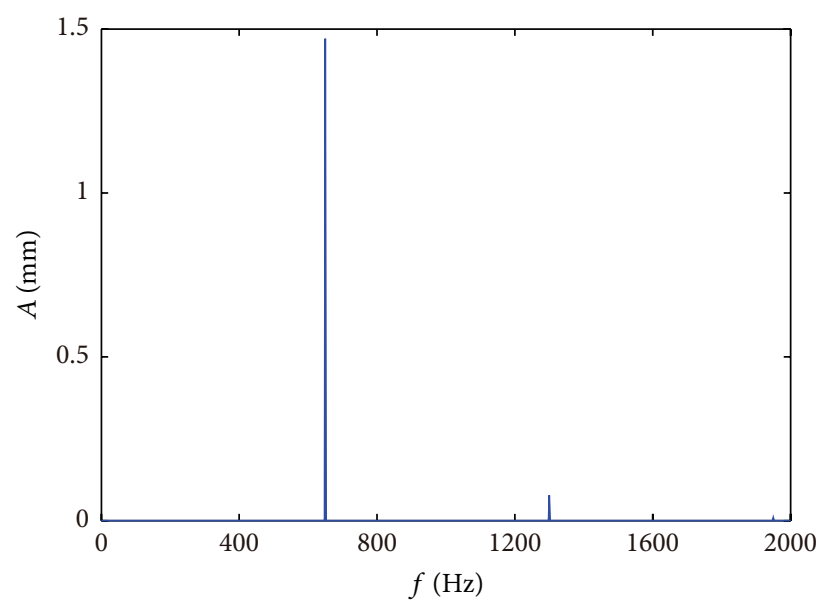

(b) Frequency spectrum plot

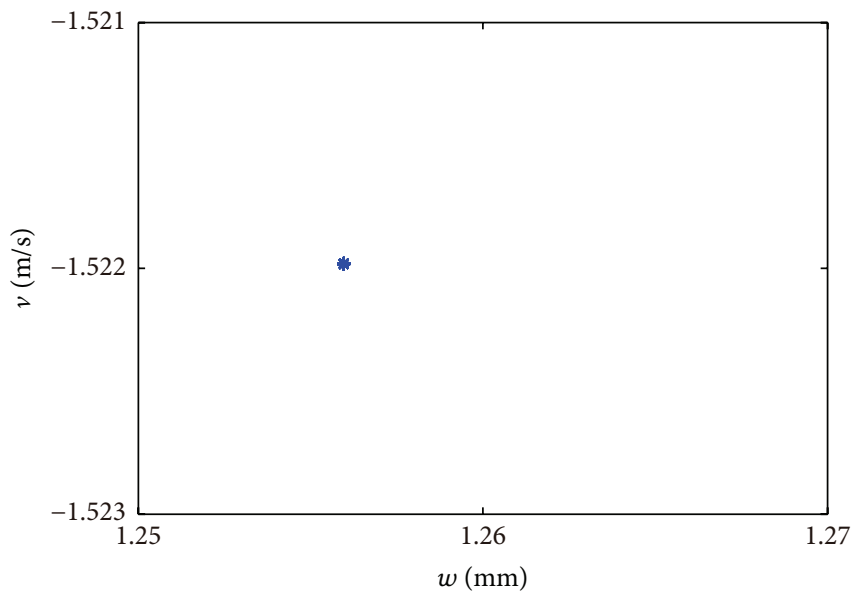

(d) Poincare section

FIGURE 24: The periodic motion of cylindrical shell at $k \leqslant 4.5 \times 10^{8} \mathrm{~N} / \mathrm{m}$. 


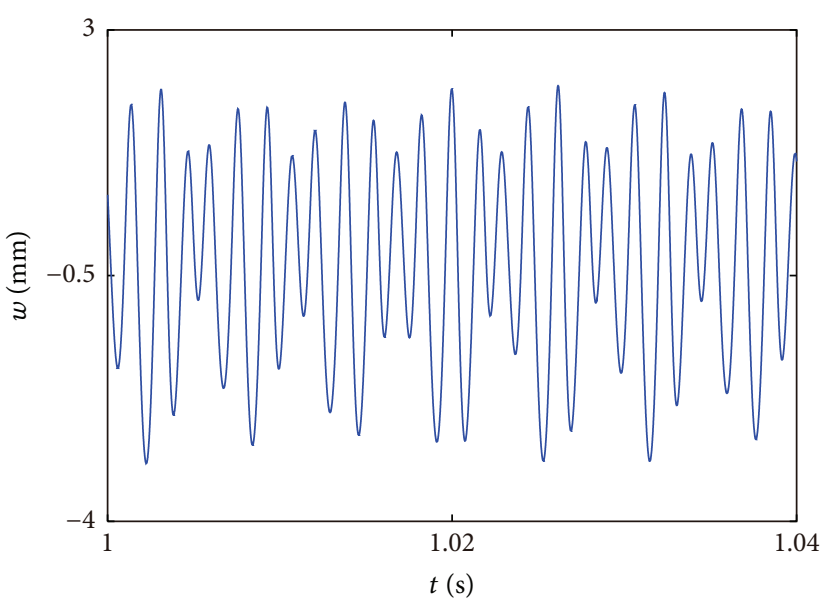

(a) Time history

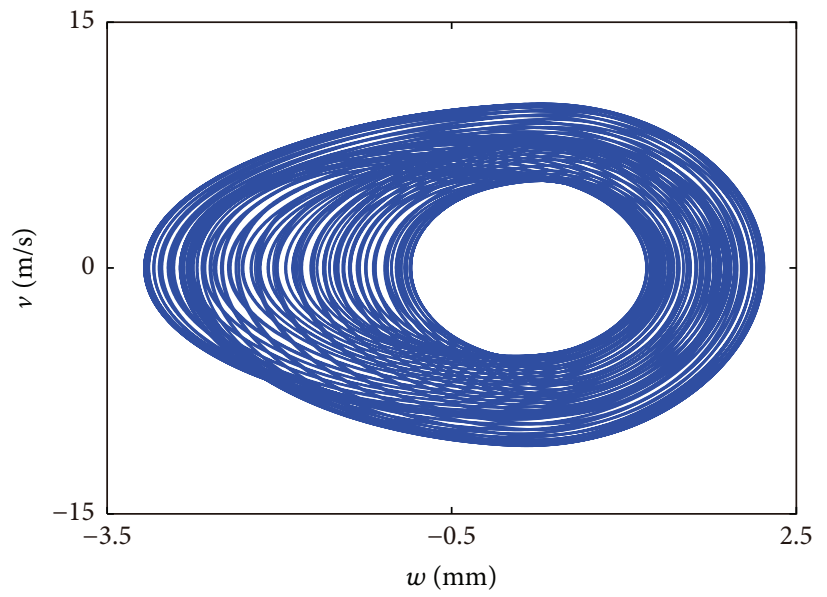

(c) Phase portraits

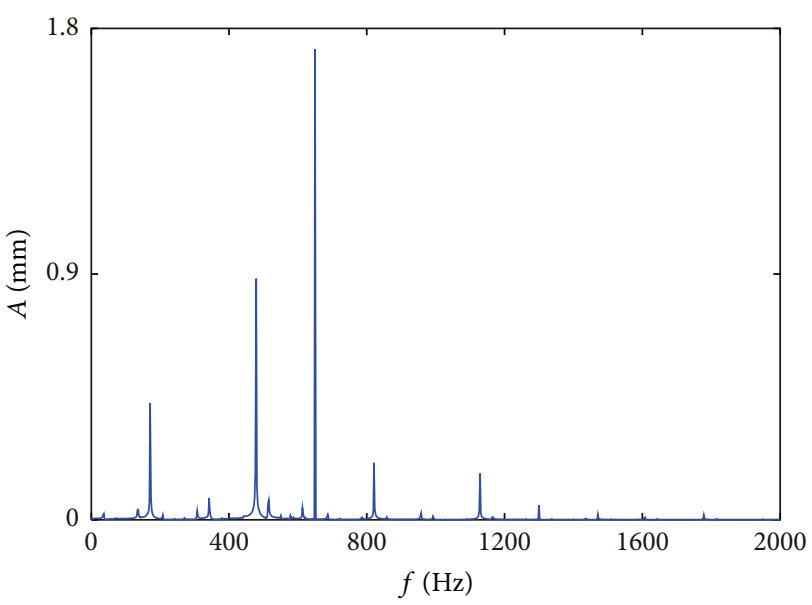

(b) Frequency spectrum plot

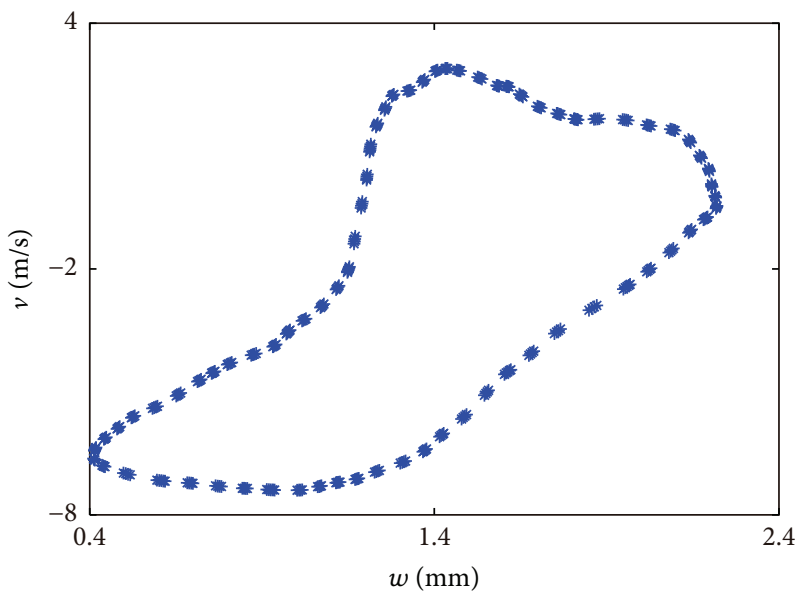

(d) Poincare section

FIGURE 25: The quasiperiodic motion of cylindrical shell at $k \leqslant 4.7 \times 10^{8} \mathrm{~N} / \mathrm{m}$.

Figure 23 shows the local bifurcation diagram in which the stiffness step is $0.05 \times 10^{7} \mathrm{~N} / \mathrm{m}$ and the local threedimensional spectrum plot in which the step is $0.2 \times 10^{7} \mathrm{~N} / \mathrm{m}$. The dynamic responses show the complexity and diversity. In the range of $4.5 \times 10^{8} \mathrm{~N} / \mathrm{m} \leqslant k \leqslant 4.6 \times 10^{8} \mathrm{~N} / \mathrm{m}$, the bifurcation diagram is a straight line, and the corresponding frequencies $\omega$ and $3 \omega$ in spectrum plot tell that it is a periodic motion. The bifurcation diagram becomes complex when the stiffness is in the interval $4.6 \times 10^{8} \mathrm{~N} / \mathrm{m} \leqslant k \leqslant$ $4.795 \times 10^{8} \mathrm{~N} / \mathrm{m}$. Because many subharmonic frequencies emerge, the response may be a quasiperiodic motion or even a chaotic motion which should be verified in depth. And similar phenomena appear in the stiffness intervals of $4.835 \times$ $10^{8} \mathrm{~N} / \mathrm{m} \leqslant k \leqslant 5.03 \times 10^{8} \mathrm{~N} / \mathrm{m}$ and $5.155 \times 10^{8} \mathrm{~N} / \mathrm{m}$ $\leqslant k \leqslant 5.245 \times 10^{8} \mathrm{~N} / \mathrm{m}$. 8T-period-doubling bifurcation, 5T-period-doubling bifurcation, and 10T-period-doubling bifurcation appear in $4.8 \times 10^{8} \mathrm{~N} / \mathrm{m} \leqslant k \leqslant 4.83 \times 10^{8} \mathrm{~N} / \mathrm{m}$, $5.035 \times 10^{8} \mathrm{~N} / \mathrm{m} \leqslant k \leqslant 5.135 \times 10^{8} \mathrm{~N} / \mathrm{m}$, and $5.25 \times 10^{8} \mathrm{~N} / \mathrm{m}$ $\leqslant k \leqslant 5.34 \times 10^{8} \mathrm{~N} / \mathrm{m}$, respectively. Lastly in the range of $k$ form $5.34 \times 10^{8} \mathrm{~N} / \mathrm{m}$ to $5.5 \times 10^{8} \mathrm{~N} / \mathrm{m}$, the bifurcation diagram is chaotic and the continuous random frequencies emerge in the three-dimensional spectrum plot; these phenomena indicate that the response may be chaotic motion. Other intervals can be analyzed by the same method.

To verify the analysis of the motion states, periodic motion, multiperiodic motion, quasiperiodic motion, or chaotic motion, deduced in the bifurcation diagram and the three-dimensional spectrum plot, time history, frequency spectrum plot, phase portraits, and Poincare section at several support stiffness in the corresponding sensitive interval were presented in Figures 24, 25, 26, 27, 28, and 29. In Figure 24, the time history approximates to a sine or cosine curve, there is not sub-harmonic frequency in frequency spectrum plot and there is only one point in Poincare section. These all indicate that the response is a periodic motion. In Figure 25, when $k \leqslant 4.7 \times 10^{8} \mathrm{~N} / \mathrm{m}$, the irregular time waveform and phase portraits, the complex subharmonic, and the closed curve in Poincare section suggest that the response is quasiperiodic motion. In Figures 26, 27, and 28, the similar phenomena can be found in time history, frequency spectrum plot, and phase portraits, but the 8 isolated points, 5 isolated points, and 10 isolated points tell that the responses are $8 \mathrm{~T}$-periodic motion, 5T-periodic motion, and 10T-periodic motion, respectively. 


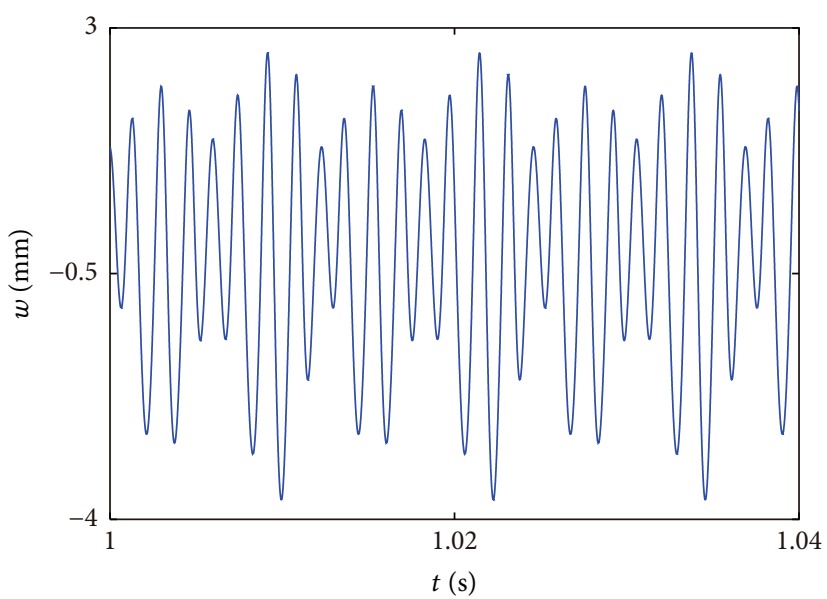

(a) Time history

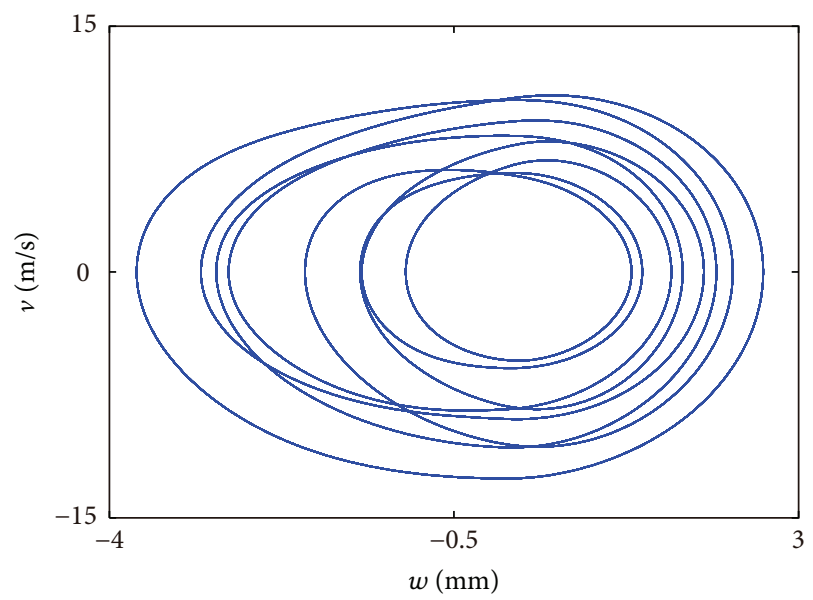

(c) Phase portraits

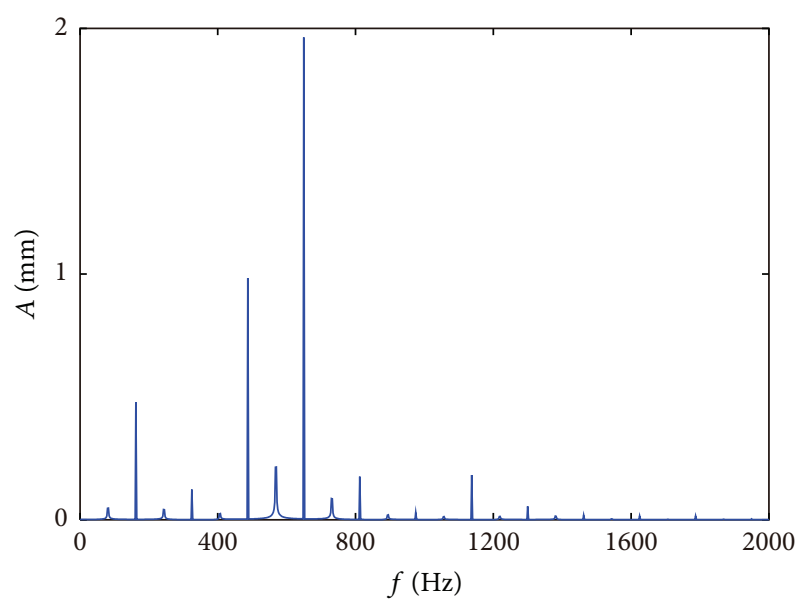

(b) Frequency spectrum plot

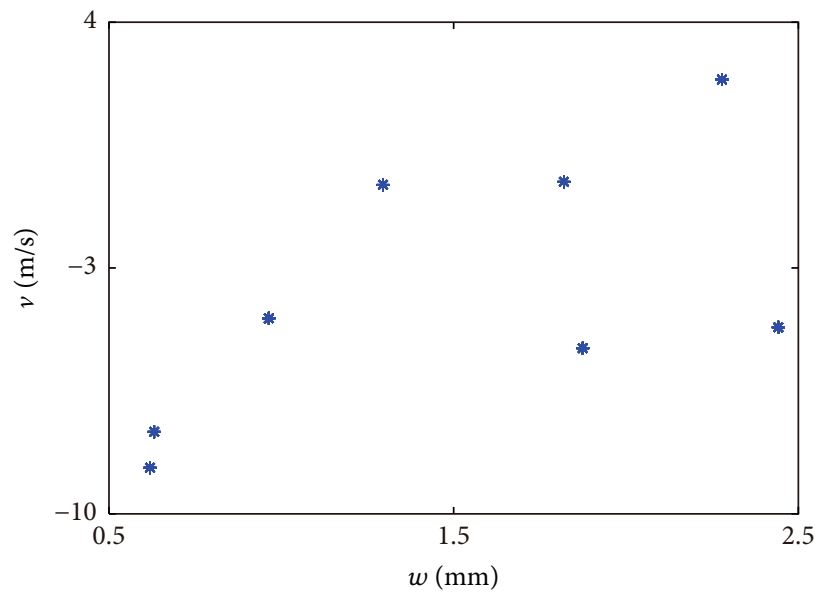

(d) Poincare section

FIgURE 26: The 8T-periodic motion of cylindrical shell at $k \leqslant 4.8 \times 10^{8} \mathrm{~N} / \mathrm{m}$.

The four figures in Figure 29 are all irregular to detect the chaotic motion of cylindrical shell at $k \leqslant 5.5 \times 10^{8} \mathrm{~N} / \mathrm{m}$.

\section{Conclusions}

In this paper, nonlinear dynamic analysis of a thin-wall cylindrical shell with nonlinear boundary condition was presented. The nonlinear boundary was considered as supported clearance in one end of the cylindrical shell. $m=1$ and $n=8$ were set to calculate the numerical results of dynamic response. And by simulation and calculation, time history, frequency spectrum plot, phase portraits, Poincare section, and bifurcation diagram were obtained.

The numerical results indicate that the cylindrical shell system with supported clearance exhibited rich nonlinear phenomena, such as the period-doubling bifurcation, the multiperiodic and the quasiperiodic motions, and the chaotic motion. This is because the supported clearance may lead to the changing of the stiffness of the nonlinear dynamic system. And through these cases and figures, the nonlinear dynamic response of cylindrical shell can be greatly influenced by external load frequency, supported clearance, and support stiffness. The dynamic behaviors of the cylindrical shell would show more complicated dynamic response in the sensitive interval of external load frequency, supported clearance, and support stiffness, for example, $260 \mathrm{~Hz} \leqslant \omega \leqslant$ $295 \mathrm{~Hz}$ in Figure 5, $0 \mathrm{~mm} \leqslant b \leqslant 0.15 \mathrm{~mm}$ in Figure 12, and $3.4 \times 10^{8} \mathrm{~N} / \mathrm{m} \leqslant k \leqslant 5.4 \times 10^{8} \mathrm{~N} / \mathrm{m}$ in Figure 23. In conclusion, nonlinear boundary such as supported clearance analyzed before exists widely in engineering. This paper developed an effective method for forced vibration of thinwall cylindrical shell with nonlinear boundary conditions. The present nonlinear model provides a prediction of the complex dynamic behavior of the system of cylindrical shell with supported clearance which may appear in actual engineering and it has great reference value for designer in designing process.

\section{Appendix}

Consider 
Shock and Vibration

19

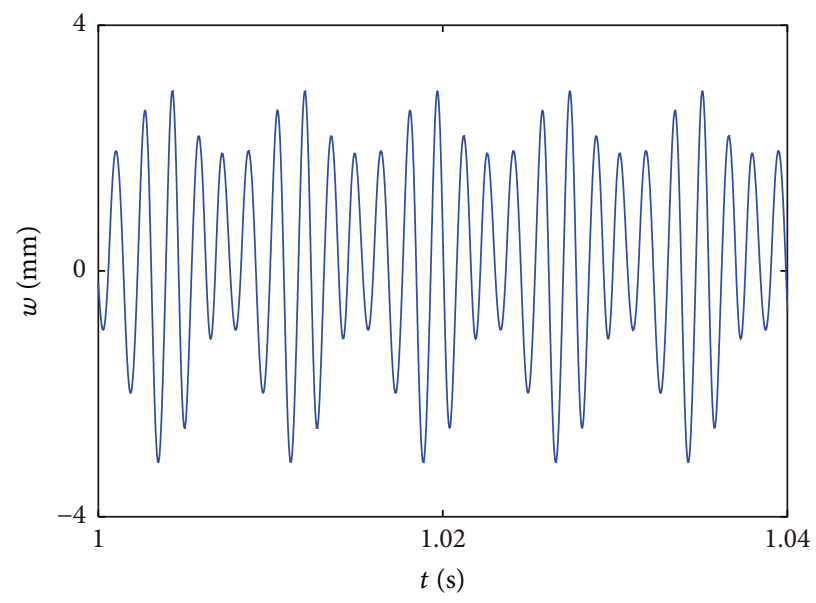

(a) Time history

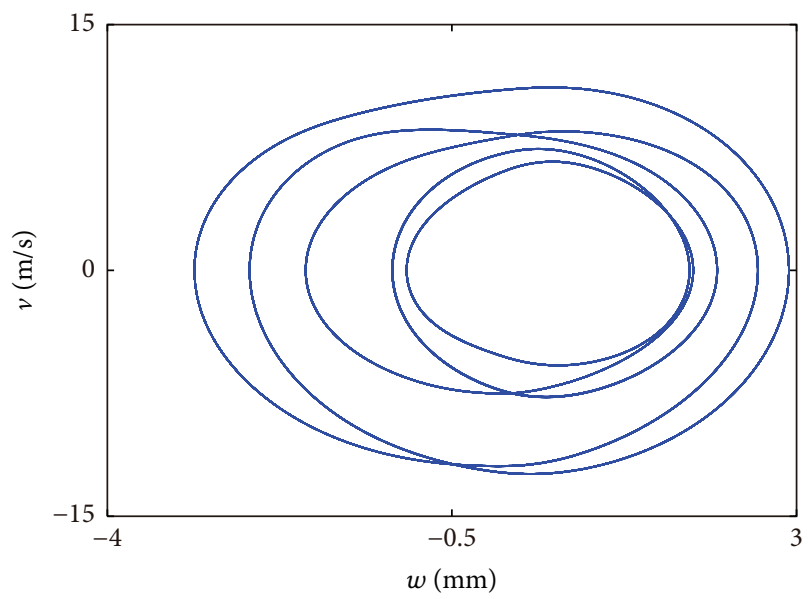

(c) Phase portraits

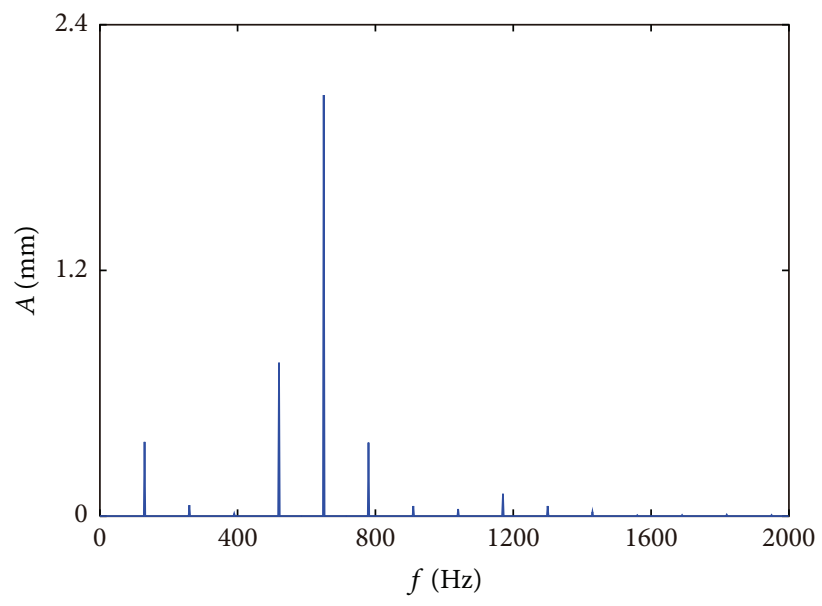

(b) Frequency spectrum plot

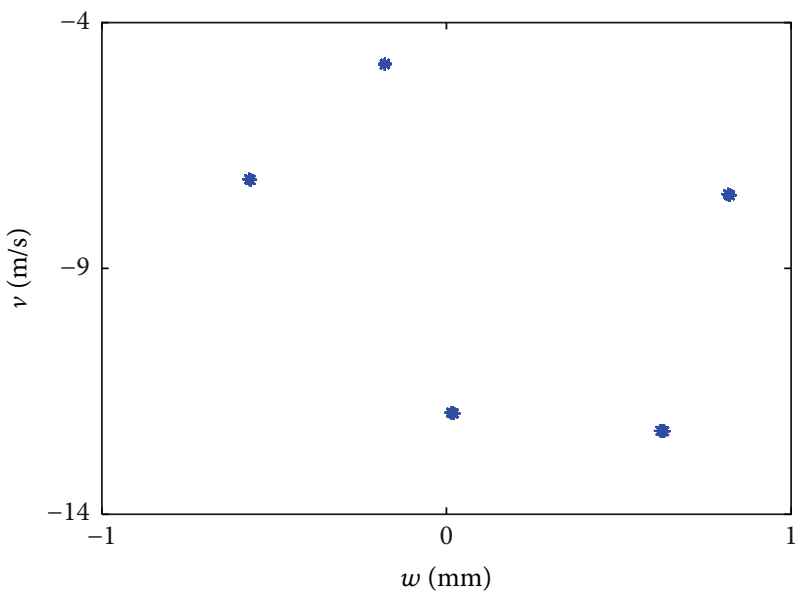

(d) Poincare section

FIgURE 27: The 5T-periodic motion of cylindrical shell at $k \leqslant 5.1 \times 10^{8} \mathrm{~N} / \mathrm{m}$.

$$
\begin{aligned}
& \mathbf{M}_{1}=\rho h \int_{0}^{L} \int_{0}^{2 \pi} \mathbf{U} \mathbf{U}^{\mathrm{T}} R \mathrm{~d} \theta \mathrm{d} x, \\
& \mathbf{M}_{2}=\rho h \int_{0}^{L} \int_{0}^{2 \pi} \mathbf{V V}^{\mathrm{T}} R \mathrm{~d} \theta \mathrm{d} x, \\
& \mathbf{M}_{3}=\rho h \int_{0}^{L} \int_{0}^{2 \pi} \mathbf{W} \mathbf{W}^{\mathrm{T}} R \mathrm{~d} \theta \mathrm{d} x, \\
& \mathbf{K}_{1}=\int_{0}^{L} \int_{0}^{2 \pi}\left\{\frac{E h}{\left(1-\mu^{2}\right)} \frac{\partial \mathbf{U}}{\partial x} \frac{\partial \mathbf{U}^{\mathrm{T}}}{\partial x}+\left[\frac{E h}{\left(1-\mu^{2}\right)} \frac{1-\mu}{2} \frac{1}{R^{2}}+\frac{E h^{3}}{12\left(1-\mu^{2}\right)} \frac{(1-\mu)}{2 R^{2}} \frac{1}{4 R^{2}}\right] \frac{\partial \mathbf{U}}{\partial \theta} \frac{\partial \mathbf{U}^{\mathrm{T}}}{\partial \theta}\right\} R \mathrm{~d} \theta \mathrm{d} x, \\
& \mathbf{K}_{2}=\int_{0}^{L} \int_{0}^{2 \pi} \frac{E h}{\left(1-\mu^{2}\right)} \frac{2 \mu}{R} \frac{\partial \mathbf{U}}{\partial x} \frac{\partial \mathbf{V}^{\mathrm{T}}}{\partial \theta}+\left[\frac{E h}{\left(1-\mu^{2}\right)} \frac{1-\mu}{2} \frac{2}{R}-\frac{E h^{3}}{12\left(1-\mu^{2}\right)} \frac{(1-\mu)}{2 R^{2}} \frac{3}{2 R}\right] \frac{\partial \mathbf{U}}{\partial \theta} \frac{\partial \mathbf{V}^{\mathrm{T}}}{\partial x} R \mathrm{~d} \theta \mathrm{d} x, \\
& \mathbf{K}_{3}=\int_{0}^{L} \int_{0}^{2 \pi}\left[\frac{E h}{\left(1-\mu^{2}\right)} \frac{2 \mu}{R} \frac{\partial \mathbf{U}}{\partial x} \mathbf{W}^{\mathrm{T}}+\frac{E h^{3}}{12\left(1-\mu^{2}\right)} \frac{(1-\mu)}{2 R^{2}} \frac{2}{R} \frac{\partial \mathbf{U}}{\partial \theta} \frac{\partial^{2} \mathbf{W}^{\mathrm{T}}}{\partial x \partial \theta}\right] R \mathrm{~d} \theta \mathrm{d} x, \\
& \mathbf{K}_{4}=\int_{0}^{L} \int_{0}^{2 \pi}\left\{\left[\frac{E h}{\left(1-\mu^{2}\right)} \frac{1}{R^{2}}+\frac{E h^{3}}{12\left(1-\mu^{2}\right)} \frac{1}{R^{4}}\right] \frac{\partial \mathbf{V}}{\partial \theta} \frac{\partial \mathbf{V}^{\mathrm{T}}}{\partial \theta}+\left[\frac{E h}{\left(1-\mu^{2}\right)} \frac{1-\mu}{2}+\frac{E h^{3}}{12\left(1-\mu^{2}\right)} \frac{(1-\mu)}{2 R^{2}} \frac{9}{4}\right] \frac{\partial \mathbf{V}}{\partial x} \frac{\partial \mathbf{V}^{\mathrm{T}}}{\partial x}\right\}
\end{aligned}
$$

$\cdot R \mathrm{~d} \theta \mathrm{d} x$ 


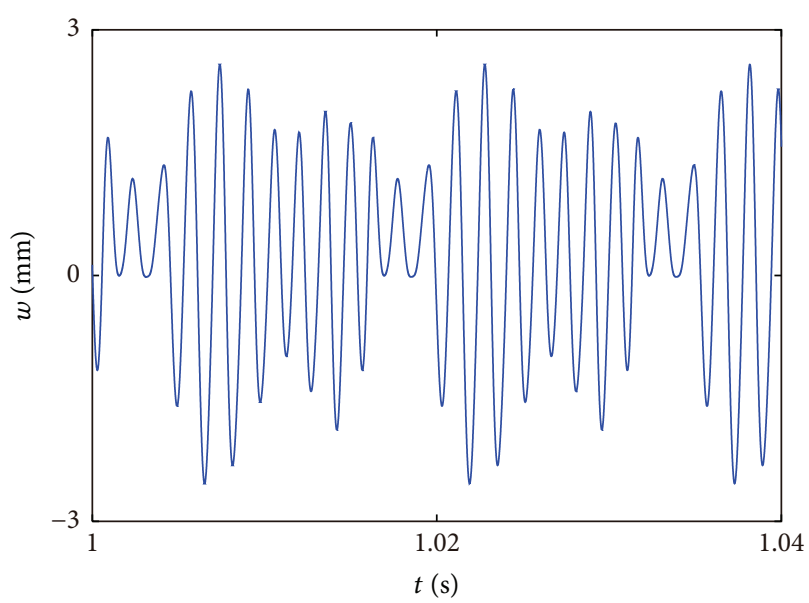

(a) Time history

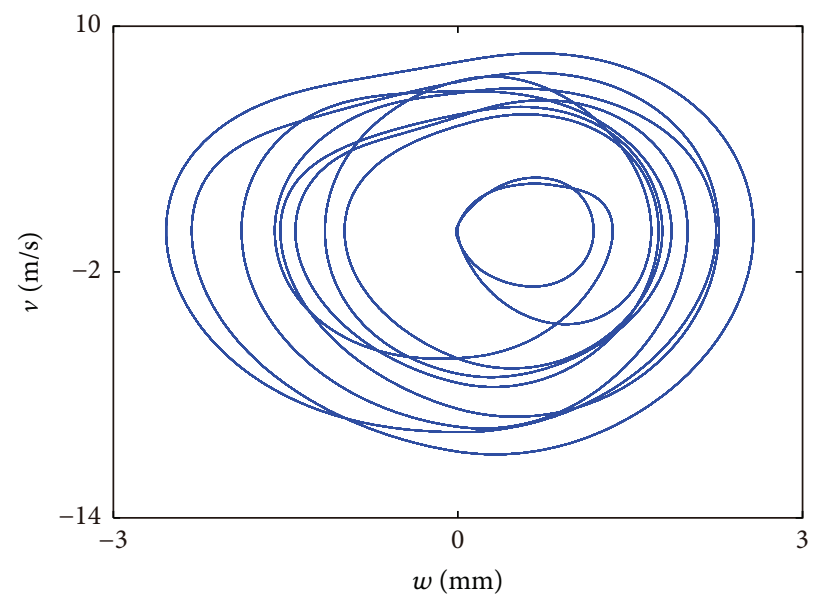

(c) Phase portraits

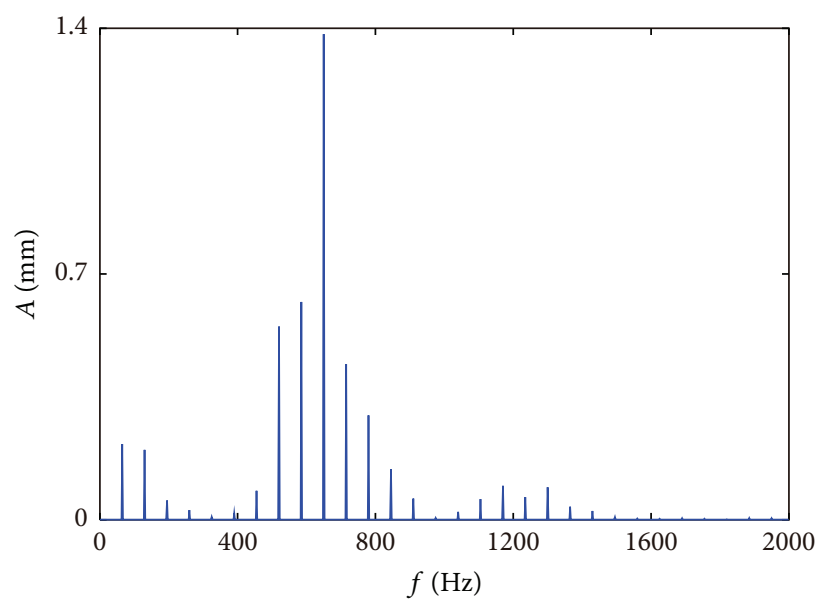

(b) Frequency spectrum plot

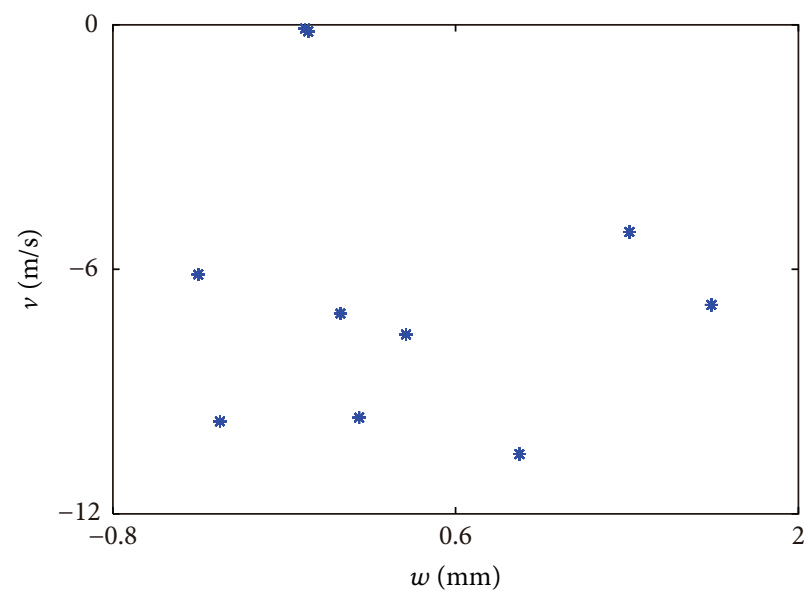

(d) Poincare section

FIGURE 28: The 10T-periodic motion of cylindrical shell at $k \leqslant 5.3 \times 10^{8} \mathrm{~N} / \mathrm{m}$.

$$
\begin{aligned}
\mathbf{K}_{5} & =\int_{0}^{L} \int_{0}^{2 \pi}\left\{\frac{E h}{\left(1-\mu^{2}\right)} \frac{2}{R^{2}} \frac{\partial \mathbf{V}}{\partial \theta} \mathbf{W}^{\mathrm{T}}-\frac{E h^{3}}{12\left(1-\mu^{2}\right)} \frac{2 \mu}{R^{2}} \frac{\partial \mathbf{V}}{\partial \theta} \frac{\partial^{2} \mathbf{W}^{\mathrm{T}}}{\partial x^{2}}-\frac{E h^{3}}{12\left(1-\mu^{2}\right)} \frac{2}{R^{4}} \frac{\partial \mathbf{V}}{\partial \theta} \frac{\partial^{2} \mathbf{W}^{\mathrm{T}}}{\partial \theta^{2}}\right. \\
& \left.-\frac{E h^{3}}{12\left(1-\mu^{2}\right)} \frac{6(1-\mu)}{2 R^{2}} \frac{\partial \mathbf{V}}{\partial x} \frac{\partial^{2} \mathbf{W}^{\mathrm{T}}}{\partial x \partial \theta}\right\} R \mathrm{~d} \theta \mathrm{d} x, \\
\mathbf{K}_{6} & =\int_{0}^{L} \int_{0}^{2 \pi}\left\{\frac{E h}{\left(1-\mu^{2}\right)} \frac{1}{R^{2}} \mathbf{W} \mathbf{W}^{\mathrm{T}}+\frac{E h^{3}}{12\left(1-\mu^{2}\right)} \frac{\partial^{2} \mathbf{W}}{\partial x^{2}} \frac{\partial^{2} \mathbf{W}^{\mathrm{T}}}{\partial x^{2}}+\frac{E h^{3}}{12\left(1-\mu^{2}\right)} \frac{2 \mu}{R^{2}} \frac{\partial^{2} \mathbf{W}}{\partial x^{2}} \frac{\partial^{2} \mathbf{W}^{\mathrm{T}}}{\partial \theta^{2}}+\frac{E h^{3}}{12\left(1-\mu^{2}\right)} \frac{1}{R^{4}} \frac{\partial^{2} \mathbf{W}}{\partial \theta^{2}} \frac{\partial^{2} \mathbf{W}^{\mathrm{T}}}{\partial \theta^{2}}\right. \\
& \left.+\frac{E h^{3}}{12\left(1-\mu^{2}\right)} \frac{4(1-\mu)}{2 R^{2}} \frac{\partial^{2} \mathbf{W}}{\partial x \partial \theta} \frac{\partial^{2} \mathbf{W}^{\mathrm{T}}}{\partial x \partial \theta}\right\} R \mathrm{~d} \theta \mathrm{d} x .
\end{aligned}
$$

\section{Competing Interests}

The authors declare that there is no conflict of interests regarding the publication of this paper.

\section{Acknowledgments}

The project was supported by Fundamental Research Funds for the Central Universities (nos. N140304002 and 


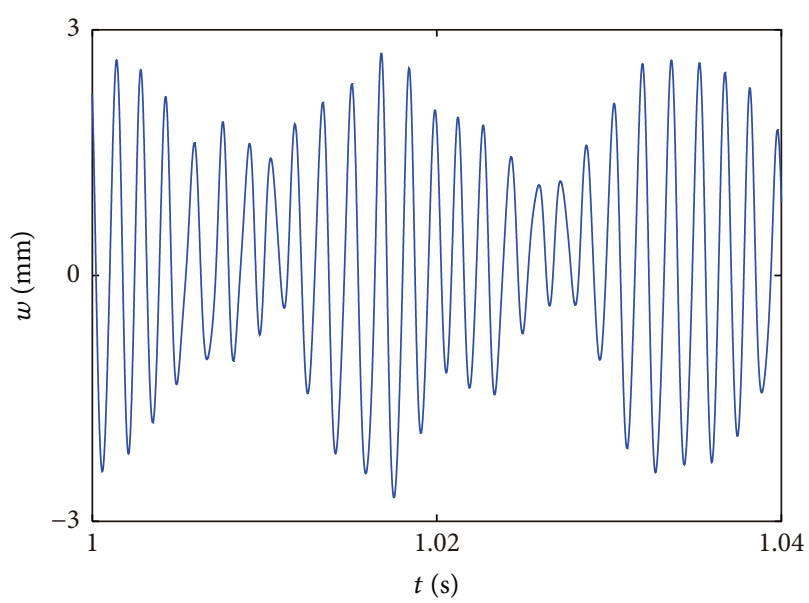

(a) Time history

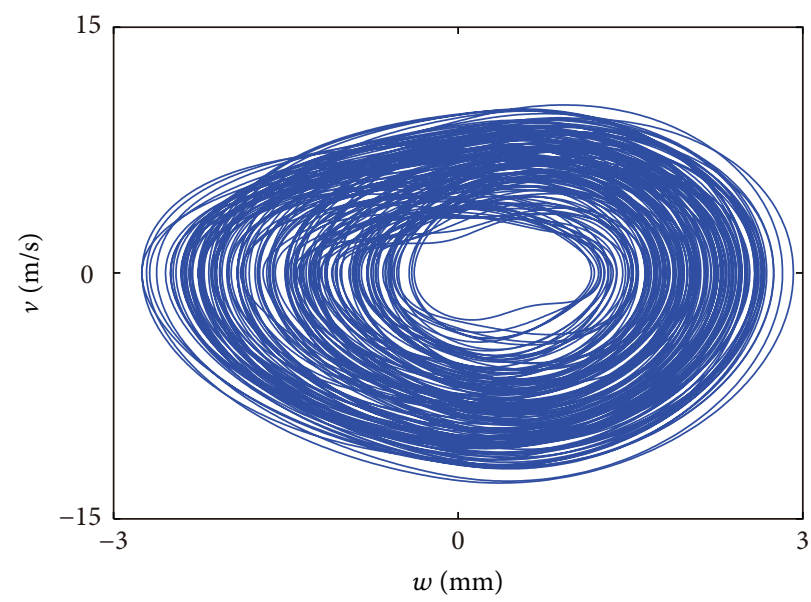

(c) Phase portraits

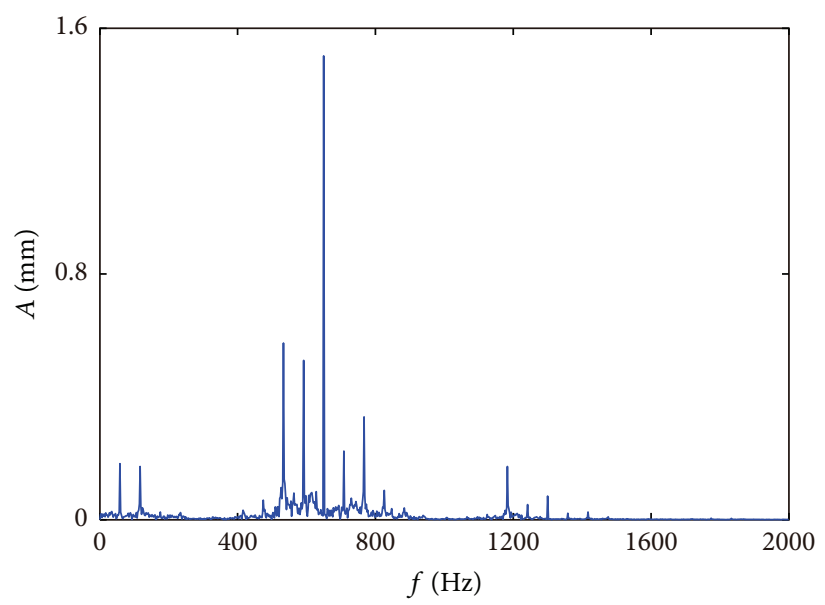

(b) Frequency spectrum plot

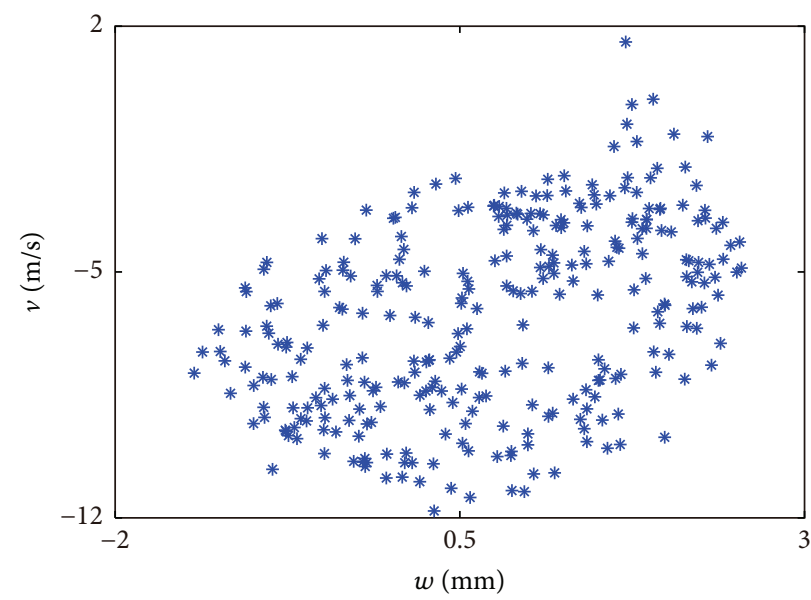

(d) Poincare section

FIgURE 29: The chaotic motion of cylindrical shell at $k \leqslant 5.5 \times 10^{8} \mathrm{~N} / \mathrm{m}$.

N140301001) and the China Natural Science Funds (no. 51575093).

\section{References}

[1] A. W. Leissa, Vibration of Shells, Acoustical Society of America, 1993.

[2] M. S. Qatu, "Recent research advances in the dynamic behavior of shells: 1989-2000, Part 2: homogeneous shells," Applied Mechanics Reviews, vol. 55, no. 5, pp. 415-434, 2002.

[3] M. S. Qatu, "Recent research advances in the dynamic behavior of shells: 1989-2000, part 1: laminated composite shells," Applied Mechanics Reviews, vol. 55, no. 4, pp. 325-349, 2002.

[4] C. T. Loy, K. Y. Lam, and C. Shu, "Analysis of cylindrical shells using generalized differential quadrature," Shock \& Vibration, vol. 4, no. 3, pp. 193-198, 1997.

[5] K. Y. Lam and C. T. Loy, "Effects of boundary conditions on frequencies of a multi-layered cylindrical shell," Journal of Sound and Vibration, vol. 188, no. 3, pp. 363-384, 1995.

[6] K. Y. Lam and C. T. Loy, "Analysis of rotating laminated cylindrical shells by different thin shell theories," Journal of Sound \& Vibration, vol. 186, no. 1, pp. 23-35, 1995.
[7] S. C. Pradhan, C. T. Loy, K. Y. Lam, and J. N. Reddy, "Vibration characteristics of functionally graded cylindrical shells under various boundary conditions," Applied Acoustics, vol. 61, no. 1, pp. 111-129, 2000.

[8] X. M. Zhang, G. R. Liu, and K. Y. Lam, "Vibration analysis of thin cylindrical shells using wave propagation approach," Journal of Sound and Vibration, vol. 239, no. 3, pp. 397-403, 2001.

[9] K. Khan, B. P. Patel, and Y. Nath, "Free and forced vibration characteristics of bimodular composite laminated circular cylindrical shells," Composite Structures, vol. 126, pp. 386-397, 2015.

[10] C. Du, Y. Li, and X. Jin, "Nonlinear forced vibration of functionally graded cylindrical thin shells," Thin-Walled Structures, vol. 78, pp. 26-36, 2014.

[11] Y. Qu, Y. Chen, X. Long, H. Hua, and G. Meng, "Free and forced vibration analysis of uniform and stepped circular cylindrical shells using a domain decomposition method," Applied Acoustics, vol. 74, no. 3, pp. 425-439, 2013.

[12] H. Dai and H. Jiang, "Forced vibration analysis for a FGPM Cylindrical Shell," Shock \& Vibration, vol. 20, no. 3, pp. 531-550, 2013. 
[13] A. H. Sofiyev, "Dynamic response of an FGM cylindrical shell under moving loads," Composite Structures, vol. 93, no. 1, pp. 58-66, 2010.

[14] R. Salahifar and M. Mohareb, "Analysis of circular cylindrical shells under harmonic forces," Thin-Walled Structures, vol. 48, no. 7, pp. 528-539, 2010.

[15] Y. Z. Liu, Y. X. Hao, W. Zhang, J. Chen, and S. B. Li, "Nonlinear dynamics of initially imperfect functionally graded circular cylindrical shell under complex loads," Journal of Sound and Vibration, vol. 348, pp. 294-328, 2015.

[16] S. M. Ibrahim, B. P. Patel, and Y. Nath, "Nonlinear periodic response of composite curved beam subjected to symmetric and antisymmetric mode excitation," Journal of Computational \& Nonlinear Dynamics, vol. 5, no. 2, pp. 1-11, 2010.

[17] S. M. Ibrahim, B. P. Patel, and Y. Nath, "On the nonlinear dynamics of oval cylindrical shells," Journal of Mechanics of Materials and Structures, vol. 5, no. 6, pp. 887-908, 2010.

[18] S. Singh, B. P. Patel, and Y. Nath, "Postbuckling of laminated shells of revolution with meridional curvature under thermal and mechanical loads," International Journal of Structural Stability and Dynamics, vol. 9, no. 1, pp. 107-126, 2009.

[19] L. Dai, T. Yang, J. Du, W. L. Li, and M. J. Brennan, "An exact series solution for the vibration analysis of cylindrical shells with arbitrary boundary conditions," Applied Acoustics, vol. 74, no. 3, pp. 440-449, 2013.

[20] H. Zhou, W. Li, B. Lv, and W. L. Li, "Free vibrations of cylindrical shells with elastic-support boundary conditions," Applied Acoustics, vol. 73, no. 8, pp. 751-756, 2012.

[21] G. Jin, T. Ye, Y. Chen, Z. Su, and Y. Yan, "An exact solution for the free vibration analysis of laminated composite cylindrical shells with general elastic boundary conditions," Composite Structures, vol. 106, pp. 114-127, 2013.

[22] G. Jin, C. Yang, Z. Liu, S. Gao, and C. Zhang, "A unified method for the vibration and damping analysis of constrained layer damping cylindrical shells with arbitrary boundary conditions," Composite Structures, vol. 130, pp. 124-142, 2015.

[23] G. Jin, T. Ye, X. Ma, Y. Chen, Z. Su, and X. Xie, "A unified approach for the vibration analysis of moderately thick composite laminated cylindrical shells with arbitrary boundary conditions," International Journal of Mechanical Sciences, vol. 75, pp. 357-376, 2013.

[24] G. Jin, T. Ye, X. Jia, and S. Gao, "A general Fourier solution for the vibration analysis of composite laminated structure elements of revolution with general elastic restraints," Composite Structures, vol. 109, no. 6, pp. 150-168, 2014.

[25] G. Jin, T. Ye, and S. Shi, “Three-dimensional vibration analysis of isotropic and orthotropic open shells and plates with arbitrary boundary conditions," Shock and Vibration, vol. 2015, Article ID 896204, 29 pages, 2015.

[26] T. Ye, G. Jin, S. Shi, and X. Ma, "Three-dimensional free vibration analysis of thick cylindrical shells with general end conditions and resting on elastic foundations," International Journal of Mechanical Sciences, vol. 84, pp. 120-137, 2014.

[27] T. Ye, G. Jin, Y. Chen, and S. Shi, "A unified formulation for vibration analysis of open shells with arbitrary boundary conditions," International Journal of Mechanical Sciences, vol. 81, no. 4, pp. 42-59, 2014.

[28] S. Sun, S. Chu, and D. Cao, "Vibration characteristics of thin rotating cylindrical shells with various boundary conditions," Journal of Sound and Vibration, vol. 331, no. 18, pp. 4170-4186, 2012.
[29] Y. Chen, G. Jin, and Z. Liu, "Free vibration analysis of circular cylindrical shell with non-uniform elastic boundary constraints," International Journal of Mechanical Sciences, vol. 74, pp. 120-132, 2013.

[30] A. Singh and L. Shen, "Free vibration of open circular cylindrical composite shells with point supports," Journal of Aerospace Engineering, vol. 18, no. 2, pp. 120-128, 2005.

[31] S. K. A. V. Singh, "Free vibration analysis of cylindrical shells supported on parts of the edges," Journal of Aerospace Engineering, vol. 23, no. 1, pp. 34-43, 2010.

[32] C. T. Loy and K. Y. Lam, "Vibration of cylindrical shells with ring support," International Journal of Mechanical Sciences, vol. 39, no. 4, pp. 455-471, 1997. 


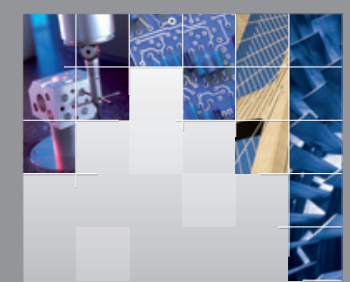

\section{Enfincering}
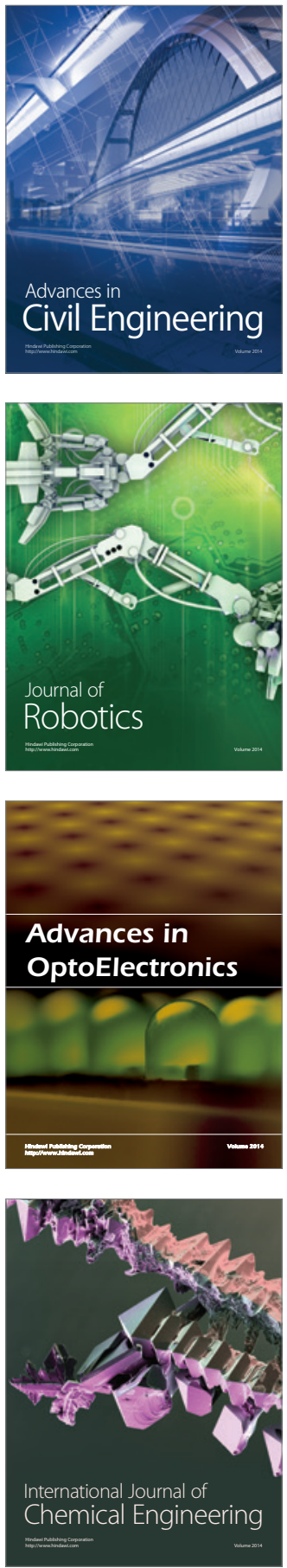

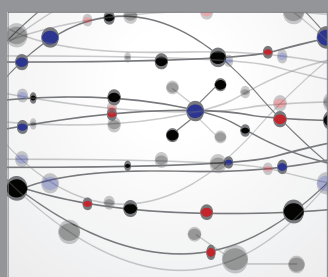

The Scientific World Journal

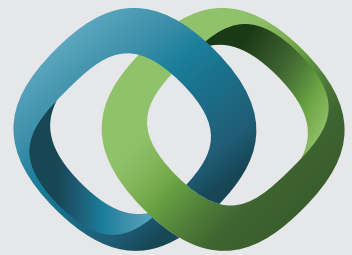

\section{Hindawi}

Submit your manuscripts at

http://www.hindawi.com
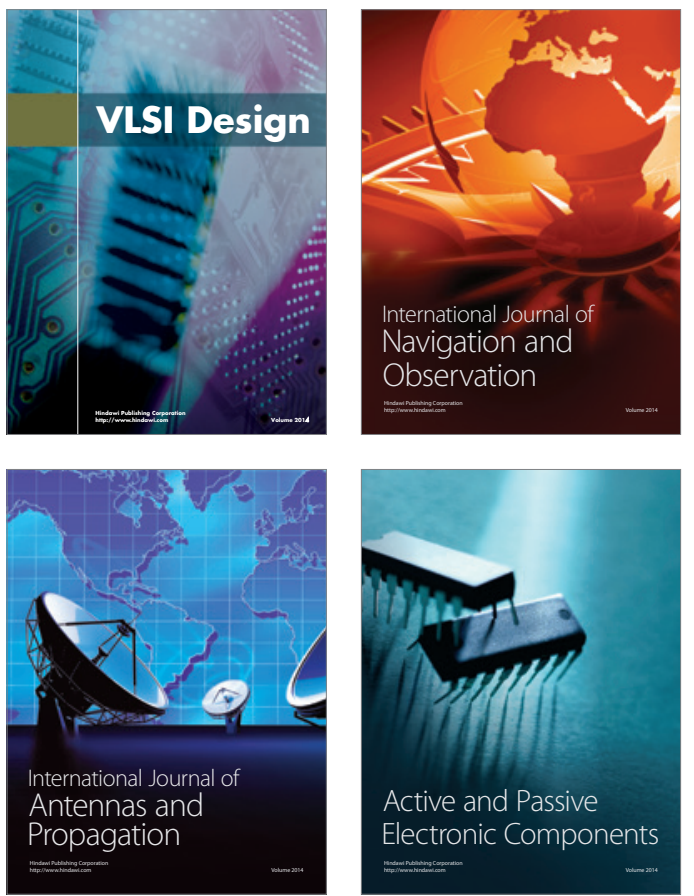
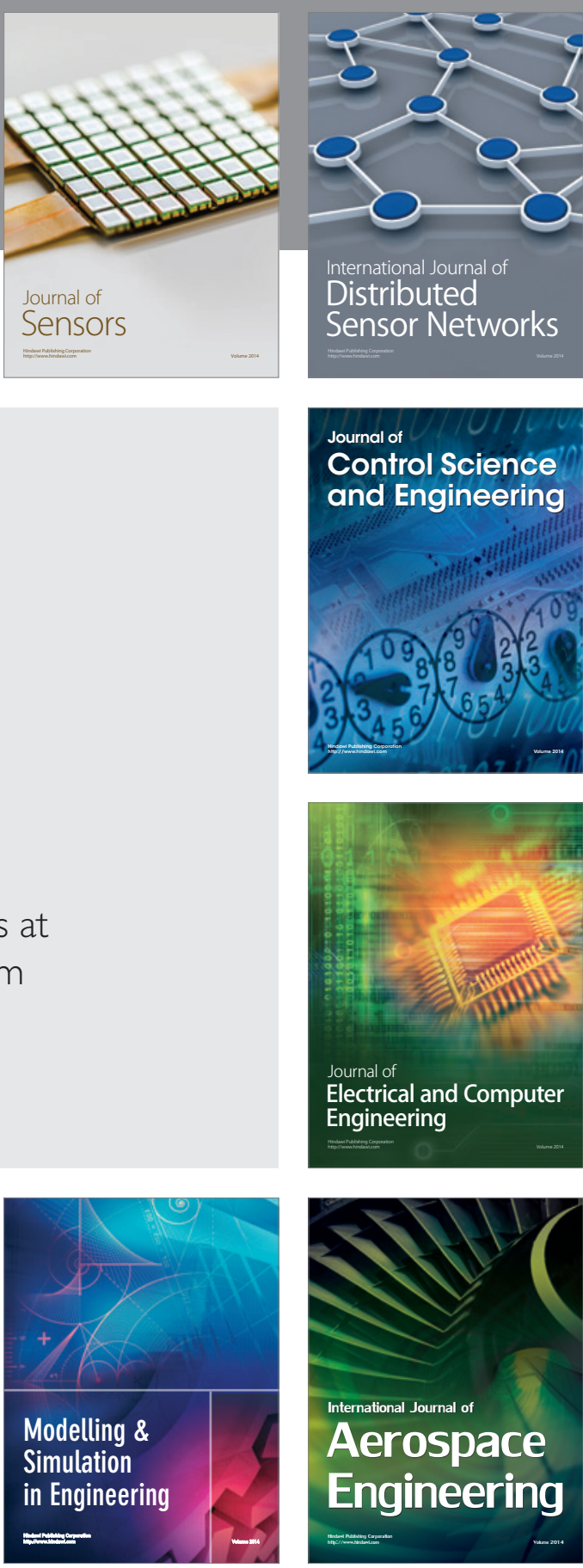

International Journal of

Distributed

Sensor Networks

Journal of

Control Science

and Engineering
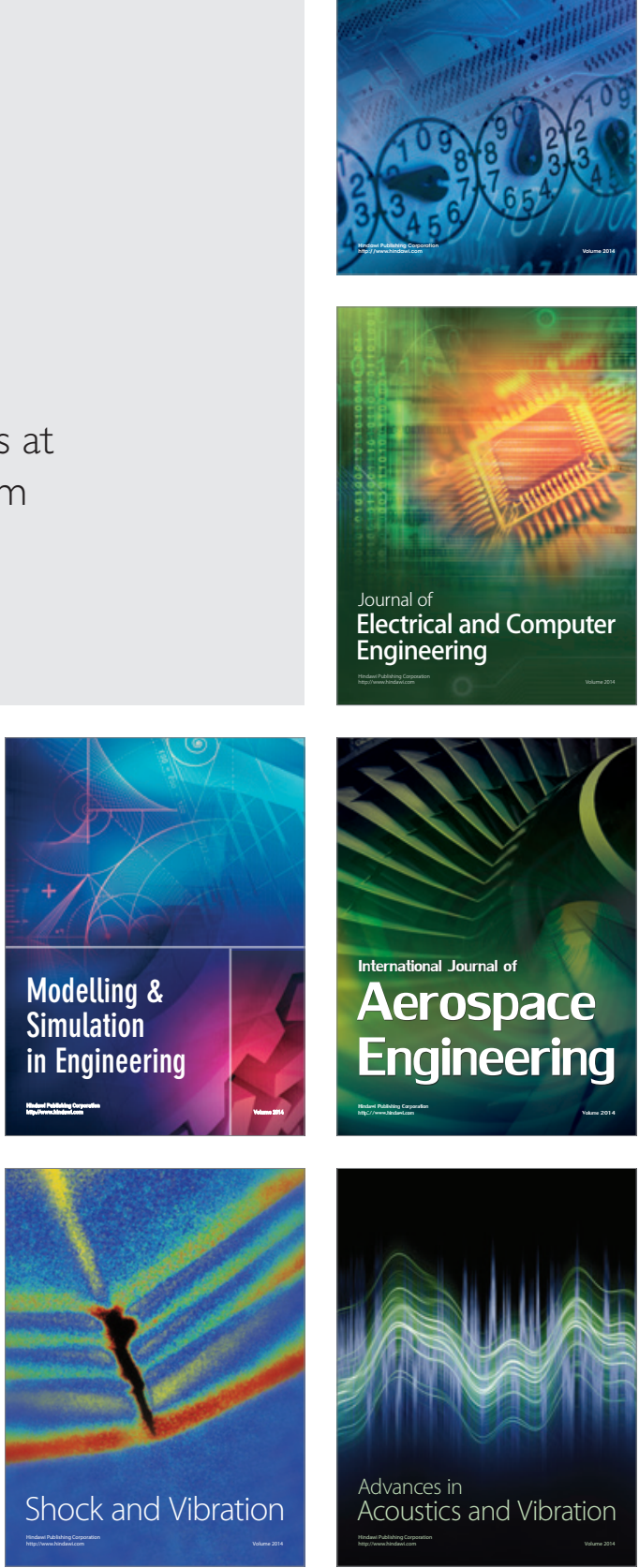